\title{
Collateralizing Liquidity
}

\author{
Cecilia Parlatore*† \\ New York University, Stern School of Business
}

April 2017

\begin{abstract}
I develop a dynamic model of optimal funding to understand why liquid financial assets are used as collateral instead of being sold to raise funds. Firms need funds to invest in risky projects with non-verifiable returns. Since holding these assets allows firms to raise these funds, firms with investment opportunities value the asset more than those without them. When investment opportunities are persistent, borrowers value the asset as a future funding source and optimally use liquid financial assets as collateral. Assets carry (funding) liquidity and collateral premia. As market liquidity increases, the liquidity premium increases while the collateral premium decreases.
\end{abstract}

*Address: 44 W4th street, suite 9-87, New York, NY, 10012. e-mail: cparlato@stern.nyu.edu, Webpage: www.ceciliaparlatore.com.

${ }^{\dagger}$ I thank Douglas Gale, Ricardo Lagos, and Thomas J. Sargent for very helpful comments and suggestions. This paper greatly benefitted from discussions with Bengt Holmstrom, Thomas Philippon, and Adriano Rampini. I also thank Viral Acharya, Bruno Biais, Saki Bigio, Alberto Bisin, Patrick Bolton, Catherine Casamatta, Eduardo Dávila, Piero Gottardi, Denis Gromb, Christian Hellwig, Wei Jiang, Todd Keister, Peter Kondor, Emiliano Catan, Antoine Martin, Alexi Savov, Michal Szkup, Felipe Varas, Neng Wang, and seminar participants at Columbia Business School, LBS, NYU, OxFIT, Stern, Toulouse School of Economics, University of Amsterdam, UCLA, UNC/Duke Corporate Finance Conference, UTDT, Wharton Conference on Liquidity and Financial Crises, and Wharton for their insightful remarks. A previous version of this paper circulated as "Equilibrium Collateral Constraints." 


\section{Introduction}

Collateralized debt is a widely used form of financing. Trillions of dollars are traded daily in debt collateralized by diverse financial assets, such as sale and repurchase agreements (repos) and collateralized over-the-counter derivative trades (see Gorton and Metrick (2012a), Gorton and Metrick (2012b), and Copeland et al. (2012)). Many financial institutions use collateralized debt to raise funds that allow them to provide intermediation services. Some of them are private depository institutions, credit unions, mortgage real estate investment trusts, and security brokers and dealers. Most of these institutions use the collateralized borrowing as a source of financing.

Crucially, the assets that are offered as collateral in collateralized derivative trades, "sold" in repos or pledged by specialty lenders to raise funds are liquid financial assets - assets that could also be sold in financial markets. In contrast to physical assets which are used as collateral to raise funds, such as family heirlooms that are pawned or real estate used to obtain credit lines, the intrinsic value of these financial assets is independent of the identity of the assets' holders. Then, why do so many financial institutions choose to use these financial assets as collateral instead of selling them to raise funds?

In this paper, I show that borrowing firms choose to collateralize liquid financial assets (rather than selling them) when the return of their investment is not contractible and investment opportunities are persistent. The non-contractibility of the investment returns implies that asset transfers, either in the form of asset sales or collateralized debt, are necessary for the firm to raise funds. Therefore, in equilibrium, the financial asset is more valuable to firms with investment opportunities. The persistence of the investment opportunities implies that borrowing firms value the asset more than the lenders because it allows them to raise funds and invest in the future. This endogenous difference in valuations leads to collateralized debt being optimal and to borrowers collateralizing liquid assets.

I develop these insights in a dynamic model of optimal funding. More specifically, in the baseline version of my model there are two periods and two risk-neutral agents, a borrower (firm) and a lender. There is also a storable consumption good and one long-term financial asset which pays dividends each period. The main difference between the financial asset and the consumption good is its pledgeability. While the asset is fully pledgeable, consumption good holdings are not 11 Each

\footnotetext{
${ }^{1}$ More generically, one could relax this assumption as long as the pledgeability of the asset is higher than the pledgeability of the consumption good.
} 
period, the borrower can invest in a risky project. This project is profitable in expectation but it incurs losses if it is not successful. The main friction in the model is that the return on the risky project is private information of the agent who invested in it and it is not verifiable. Therefore, this return is not contractible. The borrower has his investment opportunity before the financial asset's dividends are paid and, thus, cannot invest without external financing. This timing implies that, if left in autarky, both the borrower and the lender would value the asset by the expected discounted sum of dividends.

In order to raise funds and take advantage of his investment opportunity, the borrower enters into a short-term state-contingent contract with the lender. Because the return of the risky project is not contractible and the project may incur losses, the borrower cannot issue unsecured debt and he needs the pledgeable asset to raise funds to invest. Therefore, the non-contractibility of the project's return, together with the persistence of investment opportunities, implies that the borrower's valuation for the asset is higher than the value assigned by the lender. To see this, suppose that an agent in this economy will have an investment opportunity tomorrow. Holding the asset tomorrow will allow the agent to invest in the project either by selling the asset or by pledging it as collateral. Being able to raise funds against the asset in the funding market implies that an agent with an investment opportunity tomorrow will value the asset more than an agent without an investment opportunity. If investment opportunities and, thus, the role as borrower and lender are persistent, as it is the case in many collateralized debt markets, it follows that the agent who is a borrower today will value the asset higher tomorrow than the lender will ${ }^{2}$

This difference in valuations leads to the borrower optimally choosing to use liquid financial assets as collateral in the first period. If the borrower sells the asset, he can invest the net present value of the asset's dividend -the lender's valuation - in his risky project. If, instead, the borrower pledges the asset as collateral, he has incentives to repay more than the lender's valuation in order to keep the asset. The borrower only has "extra" consumption goods if the project in which he invested is successful. Therefore, using the asset as collateral makes part of the unobservable return of the risky project pledgeable and the borrower is able to invest more in his risky project by pledging the asset as collateral than by selling it.

Intuitively, when the borrower values the asset more than the lender does, selling the asset to

\footnotetext{
${ }^{2}$ This persistence is consistent with the observation that, in many collateralized debt markets, different types of institutions specialize in borrowing or lending. For example, in the repo market, money market funds are usually lenders whereas hedge funds and specialty lenders are usually borrowers.
} 
the lender is costly for the borrower. For each unit of the asset the borrower transfers to the lender, the borrower gets at most the lender's valuation, which is less than his own. Alternatively, to raise the same amount of funds, the borrower can promise to transfer consumption goods in an amount equal to the lender's valuation of the asset. Since the lender's valuation of the asset (in terms of consumption good) is lower that the borrower's, the borrower finds it less expensive to increase his funding by transferring consumption goods to the lender rather than assets. Using the asset as collateral allows the borrower to transfer the asset only in the states in which he does not have enough resources to repay the lender in consumption good.

The difference in valuations for the asset between the borrower and the lender, which is crucial for the result, arises endogenously and, as I show in this paper, it depends on whether the borrower and the lender can trade assets for consumption good after the investment opportunity's return is realized. In Section 3 , I extend the baseline model to allow for the possibility that a competitive asset market may be available at the end of the first period. Considering this market serves two purposes. First, it provides a deeper understanding of the assumptions behind the endogenous difference in valuations, which is at the center of the main result that borrowers choose to collateralize liquidity, i.e., that borrowers strictly prefer to use the liquid asset as collateral rather than selling it to raise funds. Second, it allows me to consider how the asset's market liquidity affects the financing choice of the borrower, as well as the liquidity and collateral premia ${ }^{3}$

The probability with which the market is available, which I refer to as the asset's market liquidity, is a key determinant of the marginal valuations of the asset for the borrower and the lender. As one would expect, assets with higher market liquidity allow the borrower to invest more in his project. Moreover, as long as the asset's market liquidity is not perfect, that is, as long as there is some probability that the market will not be open, the borrower values the asset more than the lender and, thus, strictly prefers to use the asset as collateral over selling it ${ }^{4}$

The extra value the borrower assigns to the asset on top of the expected discounted value of dividends can be decomposed in two premia: a (funding) liquidity premium and a collateral premium. The liquidity premium arises from the borrower being able to sell the asset and use

\footnotetext{
${ }^{3}$ Follwing Brunnermeier and Pedersen (2009) I define the asset's market liquidity as the ease with which the asset can be traded and the asset's funding liquidity as the ease with which the borrower can raise funds by selling the asset.

${ }^{4}$ Even the most liquid securities, such as US Treasuries, can become illiquid in the even of a market freeze like the one experienced during the 2008 - 2009 financial crisis.
} 
the funds to invest in his investment opportunity. The collateral premium is the additional value the borrower can obtain by using the asset as collateral instead of selling it. Interestingly, the asset's market liquidity has opposite effects on the asset premia: it increases the (funding) liquidity premium while it decreases the collateral premium.

An increase in the asset's market liquidity increases the asset's liquidity premium through two channels. First, it increases the value the lender can get for the asset, which increases the amount of funds the borrower can raise from the lender by selling his asset. Second, it increases the probability with which a borrower can use the proceeds of his risky project to buy assets which increases the borrower's value of an additional unit of funding. Both of these channels lead to an increase in the value the borrower attaches to selling the asset and, in turn, to a higher funding liquidity premium.

On the other hand, an increase in the asset's market liquidity decreases the collateral premium. The higher the probability of the market for assets being open, the smaller the difference in valuations between the borrower and the lender. The smaller this difference, the less costly it is for the borrower to transfer the asset to the lender and the lower the additional value the borrower attaches to being able to use the asset as collateral.

In the baseline two-period model, the borrower and the lender enter short-term contracts. In the paper, I show that the short-term collateralized debt contract characterized in the baseline model implements the optimal long-term contract. Intuitively, the main difference between short-term and long-term contracts is that, in long-term contracts, future loan amounts can be contingent on the current repayment by the borrower. However, since in short-term contracts the loan amount the borrower can get each period depends on his asset holdings, collateralized debt indirectly contracts on future loan amounts by making the asset transfers state contingent.

Finally, I extend the baseline model in several dimensions. First, I make the asset risky and allow for the dividends to be correlated with the return of the borrower's investment opportunity. An increase in this correlation increases the asset's debt capacity since it makes it costlier for the borrower to default. It also makes the asset better collateral. Second, I make the access to investment opportunities stochastic. As long as the access to investment opportunities is persistent, the asset will optimally be used as collateral. Lastly, I extend the baseline model to an infinite horizon model. This extension shows that future collateral premia amplify the current one and, thus, further increase the amount that can be borrowed against the asset.

The main contribution of this paper is to provide a microfoundation for the use of financial assets as collateral by focusing on the borrower's optimal financing choice. The paper is related 
to the large literature concerning the optimal financing of investment projects. For example, in a setup with asymmetric information about the quality of a productive asset, Gorton and Ordoñez (2014) show that short-term collateralized debt is optimal if lenders are willing to accept the asset as collateral without acquiring information about it. They show that this is the case if the prior about the quality of the asset used as collateral is high enough. My paper differs from Gorton and Ordoñez (2014) in three ways: (1) I consider financial assets (as opposed to physical productive ones), (2) I allow for asset sales, which they do not consider, and (3) there is perfect information about the quality of the asset in my model.

Within the literature on optimal financing, this paper is closely related to papers that consider incomplete contracts, either due to private information or moral hazard, in which the optimal contract features collateralized debt. In Bolton and Scharfstein (1990), the optimal contract is a long-term contract in which the lender commits to liquidate the borrower's firm if default occurs. In Lacker (2001), non-pecuniary costs of default are assumed while in Rampini (2005), default penalties are modeled as transfers of goods only valued by the borrower. Gale and Hellwig (1985), Bernanke and Gertler (1989) and Bernanke et al. (1998) also find optimal contracts that resemble collateralized debt. They follow Townsend (1979) and allow for costly state verification to partially resolve the agency problems. In all of these papers, including my paper, the optimal contract involves some credible punishment for the borrower if the bad state is realized, which incentivizes him to behave, and report the state truthfully. The main contribution of my paper is that the cost of default for the borrower, which is the key determinant of the optimality of collateralized debt, arises endogenously and is not assumed.

In my model, contracts are incomplete but perfectly enforceable $5^{5}$ However, as Barro (1976) shows, enforcement frictions can also give rise to collateral contracts in equilibrium. Along these lines, Stiglitz and Weiss (1981), Chan and Kanatas (1985), and Kocherlakota (2001) analyze collateral as a mechanism to enforce contracts and deter default. Kiyotaki and Moore (1997) explore the effect of collateral constraints on the business cycle, while Rampini and Viswanathan (2010) and Rampini and Viswanathan (2013) examine the capital structure of the firm. In most of these papers, the assets that are used as collateral are either illiquid or they are inputs of production, so selling them to raise funds is not an option. In contrast, in my paper the asset that is used as collateral in equilibrium is a liquid financial asset.

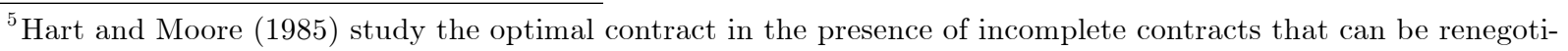
ated.
} 
One of the main advantages of deriving collateralized debt as part of the optimal contract is that the amount that can be borrowed against the asset, its debt capacity, is an equilibrium outcome. In this regard, my paper is also related to the endogenous leverage literature based on the general equilibrium models developed Araujo et al. (1994), Geanakoplos (2003a,b), Geanakoplos and Zame (1997), and Fostel and Geanakoplos (2008). In these models, the collateral requirements are also equilibrium outcomes. However, in contrast to my paper, in these papers the contract space is restricted to collateralized debt.

The mechanism I describe in this paper can be applied to multiple types of debt collateralized by financial assets, including repurchase agreements. Other papers that look specifically at repo markets are Duffie (1996), Monnet and Narajabad (2012) and Gottardi et al. (2016). Duffie (1996) argues that differences in the transactions costs between selling an asset and entering a repurchase agreement justify the use of the latter. Monnet and Narajabad (2012) look at a search model in which agents prefer to conduct repurchase agreements than asset sales when they face substantial uncertainty about the exogenous private value of holding the asset in the future. In Gottardi et al. (2016), repos allow the borrowers to insure the initial buyer of the asset against price fluctuations.

The rest of the paper is organized as follows. In Section 2, I present the baseline two-period model and highlight the mechanism behind the main result. In Section 3, I expand the baseline model by considering the possibility of a competitive asset market. Section 4 shows that the optimal short-term contracts implement the optimal long-term contracts. In Section 5, I present several model extensions that display the robustness of the main result. I conclude in Section 6. All omitted proofs are in the Appendix.

\section{Baseline model}

In this section, I present a baseline two-period model that highlights the forces behind the main result that borrowers strictly prefer to use financial assets as collateral rather than selling them to raise funds. This baseline model emphasizes the sources of the asset's funding liquidity and collateral premia that are at the core of the mechanism that makes collateralized debt optimal.

\section{$2.1 \quad$ Environment}

There are two periods, $t=1,2$, and two risk-neutral agents, a borrower $(B)$ and a lender $(L)$, with a common discount factor, $\beta \in(0,1)$. There is one non-pledgeable, storable consumption good and 
one pledgeable, long-lived financial asset in the economy ${ }^{6} a$ units of the asset yield $d a$ units of consumption good as a dividend at the end of each period $t$. The lender is endowed with a large amount of consumption good $\bar{e}$ in each period $t$. The borrower is endowed with $a_{1}^{B}$ units of the financial asset in the first period and has no consumption good endowment. Instead, in each period, the borrower has access to a risky constant return, short-term project. One unit of consumption good invested in the project at the beginning of period $t$ yields a random payoff $\theta_{t} \in\left\{\theta_{L}, \theta_{H}\right\}$ at the end of the period, where $\theta_{L}<\theta_{H}$. The projects' returns are i.i.d. over time, where the probability distribution over the returns is given by $\pi_{i} \equiv \operatorname{Pr}\left(\theta_{t}=\theta_{i}\right)$ for $i=L, H$. Though the risky project is profitable in expectation, $1<\mathbb{E}\left(\theta_{t}\right) \equiv \pi_{L} \theta_{L}+\pi_{H} \theta_{H}$, it incurs losses if the low state is realized, $0<\theta_{L}<1$. I denote by high (low) state the state in which $\theta_{t}=\theta_{H}\left(\theta_{t}=\theta_{L}\right)$.

The risky project's realized payoff is only observed by the borrower. However, the lender knows the project's return structure. More specifically, the lender knows that the borrower will get a return of at least $\theta_{L}$ per unit invested. Therefore, the borrower can credibly pledge the low return of the project to the lender but the extra return $\theta_{H}-\theta_{L}$ the project yields if the high state is realized is inalienable and not pledgeable.

The borrower can save either by storing consumption good or by holding the asset. However, given the differences in pledgeability, the borrower always prefers to save by holding assets. Since consumption good holdings are not pledgeable, the borrower cannot lever up against them. Then, the expected return of each unit of consumption good with which the borrower enters the second period is $\mathbb{E}(\theta)$. In contrast, asset holdings are pledgeable and, thus, the borrower can borrow against them. For each unit of value held in the asset the borrower can raise at least $\frac{1}{1-\theta_{L}}$ to invest in his project. Since the low return of the risky project is pledgeable $-\theta_{L}$ is common knowledgethe expected return on the funds borrowed against the asset is $\mathbb{E}(\theta)-\theta_{L}$. Then, for each unit of value held in the asset that the borrower brings to the second period, he expects a return of (at least) $\frac{\mathbb{E}(\theta)-\theta_{L}}{1-\theta_{L}}$. Since $\frac{\mathbb{E}(\theta)-\theta_{L}}{1-\theta_{L}}>\mathbb{E}(\theta)$, the borrower is always better off saving in terms of the asset rather than saving consumption good. Importantly, this implies that any convenience yield the financial asset may have is not driven by the asset's durability - the consumption good and the asset can both be stored — but by its pledgeability.7

Assumption 1 (Impatience) The discount factor $\beta$ satisfies $\beta \mathbb{E}(\theta)<1$.

\footnotetext{
${ }^{6}$ The results in the paper extend to the case in which the consumption good is pledgeable as long as the pledgeability of the consumption good is lower than the financial asset's.

${ }^{7}$ See Rampini (2016) for a discussion of the differences between pledgeability and durability.
} 
Period $t$

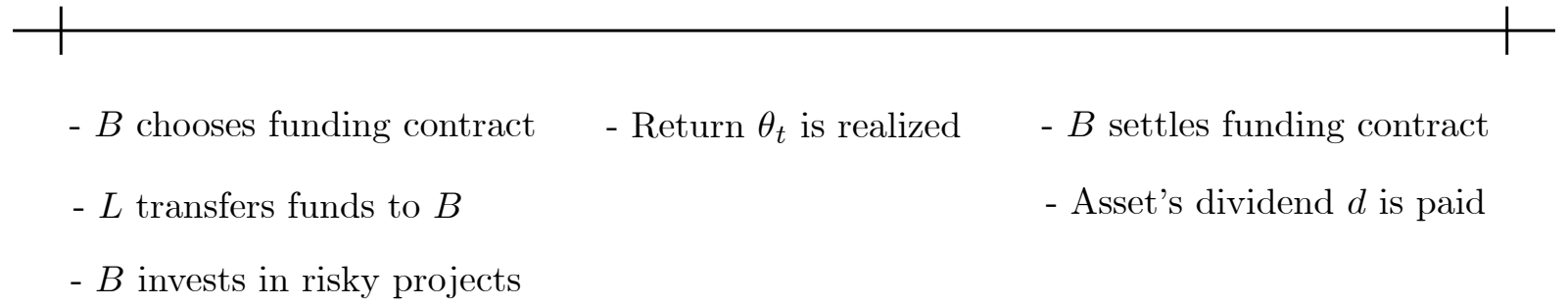

Figure 1: Timing

Assumption 1 implies that the borrower always chooses to consume the proceeds of the risky project rather than saving them to invest in his project in the future. The borrower can transfer wealth between periods either by storing consumption good or by holding the financial asset. However, given Assumption 1, the borrower finds it suboptimal to store consumption good and will always choose to begin period 2 with no consumption good. Therefore, I will ignore the borrower's consumption good saving decisions in the remainder of the paper 8

At the beginning of each period $t$, the borrower and the lender enter into a short-term funding contract in which all bargaining power is given to the borrower. After the terms of the funding contract have been determined, the borrower invests in his risky project. Once the return of the project is realized, the terms of the contract are settled and the financial asset's dividend is paid. This timing is depicted in Figure 1.

The (financial) asset's dividends are paid after the investment is made. This timing has two important implications. First, if left in autarky, the borrower and the lender value the asset equally as the discounted sum of its dividends. There is no intrinsic difference in asset valuations between the borrower and the lender. Second, the borrower needs to get funds from the lender in order to take advantage of his investment opportunity.

Definition 1 (Short-term funding contract) A short-term funding contract consists of a funding amount in terms of consumption goods, q, contingent repayments in terms of consumption goods, $r_{i}$, and in terms of asset transfers, $t_{i}, i=L, H$. Repayments in terms of assets include the transfer of the contemporaneous asset's dividends 9

\footnotetext{
${ }^{8}$ Given the linearity of the model, Assumption 1 is made for convenience. Since consumption good saving decisions do not interact with the borrower's funding choice, the results in the paper remain valid if this assumption is relaxed.

${ }^{9}$ This assumption is without loss of generality since the dividends are observable and, thus, pledgeable.
} 
In the context of the funding contract in Definition 1, I will interpret non-contingent asset transfers as asset sales and contingent asset transfers as collateralized loans in which the asset is transferred if default occurs. More specifically, when $t_{L} \neq t_{H}$, part of the asset transfers are contingent and the funding contract can be implemented using collateralized loans, as follows. If $t_{L}<(>) t_{H}$, the repayment of the collateralized part of the loan is $\left|r_{H}-r_{L}\right|$ in terms of consumption goods in the high (low) state, when there is no default, and $\left|t_{H}-t_{L}\right|$ in terms of asset transfers in the low (high) state, when default occurs.

The set of transfers implied by any contract to which the borrower and lender agree to have to be feasible given the resources held by both parties.

Definition 2 (Feasibility) A short-term contract $\left(q, r_{L}, r_{H}, t_{L}, t_{H}\right)$ is feasible in period $t$ if

$$
\begin{array}{ll}
0 \leq q \leq \bar{e} & \\
0 \leq r_{i} \leq d\left(a_{t}-t_{i}\right)+\theta_{i} q & i=L, H \\
0 \leq t_{i} \leq a_{t} & i=L, H
\end{array}
$$

where $a_{t}$ is the amount of assets held by the borrower in period $t$.

The first constraint in Definition 2 states that the funding amount $q$ has to be non-negative and that it cannot be larger than the lender's endowment of the consumption good. The second set of constraints implies that the state contingent repayments in terms of consumption goods cannot be negative, nor can they be more than the amount of the good the borrower has at the end of the period in each state after the asset transfer $t_{i}$. Similarly, the third set of constraints implies that the borrower cannot transfer more assets than the amount he holds and does not allow the borrower to purchase assets from the lender at the time of settlement. In the model developed in Section 3 . I consider the case in which the borrower can use the proceeds of this investment opportunity to purchase assets.

The non-contractibility of the returns of the risky project is the key friction that gives rise to collateralized debt in equilibrium. Since the return of the risky project is only observed by the borrower who invested in it and it is not verifiable by the lender, it is not contractible. This means that the loan contract between the lender and the borrower cannot be contingent on the realization of the return, $\theta_{t}$. However, a contract can be made contingent on the reported return of the risky project as long as it is incentive compatible. 
Definition 3 (Incentive Compatibility) A contract $\left(q, r_{L}, r_{H}, t_{L}, t_{H}\right)$ is incentive compatible in period $t$ if whenever $r_{L} \leq \theta_{H} q+d\left(a-t_{L}\right)$

$$
-r_{L}-d t_{L}+\beta V_{t+1}^{B}\left(a-t_{L}\right) \leq-r_{H}-d t_{H}+\beta V_{t+1}^{B}\left(a-t_{H}\right)
$$

and whenever $r_{H} \leq \theta_{L} q+d\left(a-t_{H}\right)$

$$
-r_{H}-d t_{H}+\beta V_{t+1}^{B}\left(a-t_{H}\right) \leq-r_{L}-d t_{L}+\beta V_{t+1}^{B}\left(a-t_{L}\right)
$$

where $V_{t+1}^{B}(a)$ is the value for a borrower with a units of the financial asset in period $t+1$.

If the borrower reports state $i$ as being realized, he transfers $r_{i}$ units of the consumption good and $t_{i}$ units of the financial asset to the lender. Since the transfer of the asset also implies the transfer of the asset's dividends, transferring $t_{i}$ units of the asset decreases the borrower's current consumption in $d t_{i}$, on top of reducing the stock of capital with which the borrower begins the following period.

The first constraint $I C_{H}$ states that, in the high state, it is always at least as good for the borrower to tell the truth and report that the high state has occurred than to lie and report a low realization of $\theta$. The second constraint $I C_{L}$ states the analogous for the low state. Note that the constraints $I C_{H}$ and $I C_{L}$ are only active when lying in the low state is feasible (i.e., when there are enough resources in the low (high) state to match the contingent repayment in terms of goods promised in the high (low) state, $r_{H}\left(r_{L}\right)$ ).

Three features of the model are worth emphasizing:

Financial assets. The long-lived asset $a$ is a financial asset. It is not related to the project available to the borrower: the asset is not an input needed to operate the project. This assumption differentiates this paper from other papers of collateral in which the asset used as collateral is a physical asset, which is physically needed to operate the borrower's technology and, thus, cannot be sold without forgoing access to the investment opportunity.

Pledgeability. The main difference between the consumption good, which can be interpreted as cash, and the financial asset is its pledgeability (recall that both the asset and the consumption good can be stored). While the borrower can commit to transferring the asset at the time of settlement, the consumption good is non-pledgeable. If one thinks of examples of cash that are pledgeable, such as cash in escrow, one can see that, in most cases, these are financial assets since cash is securitized in order to be pledged. Moreover, this assumption implies that the borrower 
prefers to transfer value across periods by saving in assets instead of in consumption goods, as discussed above.

Asset sales and liquidity. Though there is no formal market for the asset at the beginning of the period, the borrower can always sell his asset holdings at a price equal to the present value of its dividends by setting $t_{L}=t_{H}=a$ and $r_{L}=r_{H}=0$, which satisfies feasibility and incentive compatibility. Therefore, the durable financial asset is liquid - it can be sold - at the time at which the borrower makes his financing decision.

\subsection{Equilibrium}

In this section, I define and compute the equilibrium of the baseline model. I start by looking at the last period and show than the asset carries a (funding) liquidity premium for the borrower since it allows him to raise funds to invest in his risky project. Then, I look at the equilibrium in the first period and get to the main result that borrowers strictly prefer to use financial assets as collateral rather than selling them to raise funds.

\subsubsection{Second period}

In the second period, $t=2$, the borrower chooses a feasible, incentive compatible, short-term contract to maximize his expected consumption. He invests the loan amount $q$ in his risky project which yields an expected return $\mathbb{E}(\theta) q$. The borrower expects to repay $\pi_{L} r_{L}+\pi_{H} r_{H}$ in terms of consumption goods and to transfers $t_{i}$ units of the asset if state $i=L, H$ is realized. Finally, he also gets the dividends paid by his asset holdings, $d a$. Thus, a borrower with assets $a$ solves the following problem in period 2 :

$$
V_{2}^{B}(a)=\max _{q, r_{L}, r_{H}, t_{H}, t_{L}} \mathbb{E}(\theta) q-\pi_{L}\left(r_{L}+d t_{L}\right)-\pi_{H}\left(r_{H}+d t_{H}\right)+d a,
$$

subject to the short-term funding contract $\left(q, r_{L}, r_{H}, t_{H}, t_{L}\right)$ being feasible and incentive compatible, and satisfying the lender's participation constraint:

$$
q \leq \pi_{L}\left(r_{L}+d t_{L}\right)+\pi_{H}\left(r_{H}+d t_{H}\right)
$$

Proposition 1 The equilibrium short-term funding contract in period 2 is given by:

$$
\begin{aligned}
q_{2}^{*}(a) & =\frac{d a}{1-\theta_{L}}, \\
r_{2 L}^{*}(a) & =\theta_{L} q_{2}^{*}(a), \quad t_{2 L}^{*}(a)=a, \quad \text { and } \\
r_{2 H}^{*}(a)+d t_{2 H}^{*}(a) & =q_{2}^{*}(a) \text { for any } t_{2 H}^{*}(a) \in[0, a],
\end{aligned}
$$


and it can be implemented by a combination of risk-free debt at zero interest rate and either asset sales or collateralized debt.

The proof of Proposition 1 is straightforward. Since the asset has no value after the second period, incentive compatibility in the second period implies that the funding contract is risk-free for the lender, i.e., $r_{L}+d t_{L}=r_{H}+d t_{H}$. Moreover, the borrower promises to repay the maximum amount he can credibly commit to repaying in the low state, i.e., $r_{L}+d t_{L}=d a+\theta_{L} q$. This, together with the participation constraint for the lender, implies:

$$
q_{2}^{*}(a)=\pi_{L}\left(r_{2 L}^{*}(a)+d t_{2 L}^{*}(a)\right)+\pi_{H}\left(r_{2 H}^{*}(a)+d t_{2 H}^{*}(a)\right)=\frac{d a}{1-\theta_{L}} .
$$

As the Proposition 1 states, there are many transfer schemes through which the borrower can implement the optimal funding contract. In what follows, I will concentrate on the implementation with the maximum amount of risk-free debt.

Lemma 1 In any implementation of the equilibrium funding contract, the interest rate on risk-free debt has to be zero.

In any implementation, lenders have to be indifferent between lending at the risk-free rate and taking on some risk. Since the expected return of the optimal loan contract for lenders is 0 (the participation constraint for the lender is binding), the risk-free rate has to be zero.

Corollary 1 In period 2, the borrower is indifferent between selling his assets and pledging them as collateral.

The maximum amount that the borrower can repay the lender in consumption goods independent of the realized state is $r_{2 L}^{*}(a)$ (note that $r_{2 L}^{*}(a) \leq r_{2 H}^{*}(a)$ ). Since the risk-free rate is zero, the maximum amount of riskless debt is $r_{2 L}^{*}(a)$. The remaining part of the loan amount, $q_{2}^{*}(a)-r_{2 L}^{*}(a)$, can be thought of either as the proceeds from asset sales, i.e., setting $t_{2 L}^{*}=t_{2 H}^{*}=a$, or as debt collateralized by $a$ units of the asset, i.e., setting $t_{2 L}^{*}=a$ and $t_{2 H}^{*}=0$. This shows that the borrower is indifferent between selling his assets and pledging them as collateral in the second period.

Funding liquidity premium The value for a borrower of holding assets $a$ in period 2 is:

$$
V_{2}^{B}(a)=\left(\mathbb{E}(\theta)-\theta_{L}\right) \frac{d a}{1-\theta_{L}}>d a
$$


In the second period, the borrower values the asset more than the dividends it pays since having the asset allows him to raise funds and take advantage of his investment opportunity. Since the returns of the risky project are non-contractible, without the asset, the borrower would only be able to credibly commit to repaying the lender $\theta_{L}<1$ per unit borrowed and, therefore, the lender would never agree to providing an unsecured loan. Having the asset allows the borrower to pledge the asset's dividends, either by selling the asset or by using it as collateral, which in turn allows the borrower to lever up. In this case, even if the borrower always reports the low state being realized, the lender can collect $\theta_{L} q+d a$. For every unit of dividend the borrower has, he can raise $\frac{1}{1-\theta_{L}}$ units of funds from the lender. Thus,

$$
q_{2}^{*}(a)=\frac{d a}{1-\theta_{L}}
$$

Finally, since the return in the low state $\theta_{L}$ is always pledged by the borrower, the borrower gets an expected return $\mathbb{E}(\theta)-\theta_{L}$ per unit invested in his risky project. Thus, the borrower's marginal valuation of the asset at $t=2$ is $\frac{\mathbb{E}(\theta)-\theta_{L}}{1-\theta_{L}} d>d$. This extra value the borrower attaches to the asset is what I refer to as a (funding) liquidity premium. It is the additional value the borrower gets from being able to raise funds by selling the asset at the beginning of the period and investing the proceeds from the sale in his risky project. The funding liquidity premium is defined as follows:

$$
v_{2}^{B}-d=\frac{\mathbb{E}(\theta)-1}{1-\theta_{L}} d
$$

where $v_{2}^{B}$ is the borrower's marginal value of the asset at the beginning of $t=2$. The liquidity premium is equal to the levered expected excess return of the risky project times the fundamental value of the asset.

Remark If the borrower was not able to sell the asset at the beginning of $t=2$, he would value it $d$ and the liquidity premium would be zero.

\subsubsection{First period}

Analogous to the problem in the second period, in the first period the borrower solves $V_{1}^{B}(a)=\max _{q, r_{L}, r_{H}, t_{H}, t_{L}} \mathbb{E}(\theta) q-\pi_{L}\left(r_{L}+d t_{L}\right)-\pi_{H}\left(r_{H}+d t_{H}\right)+d a+\pi_{L} \beta V_{2}^{B}\left(a-t_{L}\right)+\pi_{H} \beta V_{2}^{B}\left(a-t_{H}\right)$, subject to the short-term funding contract $\left(q, r_{L}, r_{H}, t_{H}, t_{L}\right)$ being feasible and incentive compatible and satisfying the lender's participation constraint:

$$
q \leq \pi_{L}\left(r_{L}+d t_{L}+\beta V_{2}^{L}\left(t_{L}\right)\right)+\pi_{H}\left(r_{H}+d t_{H}+\beta V_{2}^{L}\left(t_{H}\right)\right)
$$


where $V_{2}^{L}(a)=d a$ is the value of a lender who owns $a$ units of the asset at the beginning of $t=2$.

Proposition 2 The equilibrium short-term funding contract in period 1 is given by

$$
\begin{array}{ll}
q_{1}^{*}(a)=\frac{(1+\beta) d a+\beta \pi_{H}\left(V_{2}^{B}(a)-V_{2}^{L}(a)\right)}{1-\theta_{L}} & \\
r_{1 L}^{*}(a)=\theta_{L} q_{1}^{*}(a), & t_{1 L}^{*}(a)=a \\
r_{1 H}^{*}(a)=r_{1 L}^{*}(a)+d a+\beta V_{2}^{B}(a), \text { and } & t_{1 H}^{*}(a)=0,
\end{array}
$$

and it can be implemented by a combination of risk-free debt at zero interest and collateralized debt.

As the proposition above states, the total size of the loan the borrower can procure from the lender in the first period depends on the resources he can credibly pledge. Since the low return $\theta_{L}$ is pledgeable, the borrower can always commit to repay at least $\theta_{L} q_{1}$ in terms of consumption goods.

By choosing to sell his assets and setting $t_{1 L}(a)=t_{1 H}(a)=a$, the the borrower can indirectly pledge the assets' dividends in periods 1 and 2. Selling the asset allows the borrower to increase the loan size in $d+\beta v_{2}^{L}$ per unit of asset sold, where $v_{2}^{L}$ is the lender's marginal valuation for the asset in period 2 .

However, transferring the asset to the lender is costly for the borrower. For each unit of the asset the borrower transfers to the lender, he gets the lender's marginal valuation, $d+\beta v_{2}^{L}$, which is less than his own marginal valuation, $d+\beta v_{2}^{B}$. Alternatively, the borrower can increase the size of the loan in the same amount by transferring the lender $d+\beta v_{2}^{L}$ units of consumption goods. Thus, the borrower would rather repay the lender in consumption goods than in assets whenever possible. This implies $t_{1 L}=a, t_{1 H}=0$ and $r_{1 H}>r_{1 L}=\theta_{L} q_{1}$. The difference in marginal valuations referred to above allows the borrower to credibly commit to a state-contingent contract by effectively pledging part of the non-pledgeable return of his project if the high state is realized.

The additional amount the borrower is willing to pay in terms of consumption goods in order not to loose the asset in the high state is $\beta\left(V_{2}^{B}(a)-V_{2}^{L}(a)\right)$. Then, the extra amount the borrower can get from the lender by pledging the asset as collateral instead of selling it is:

$$
\Delta q^{*}=\beta \pi_{H}\left(V_{2}^{B}(a)-V_{2}^{L}(a)\right)>0 .
$$

Corollary 2 In period 1, the borrower strictly prefers to pledge his assets as collateral rather than selling them. 
Equivalent to the implementation of the optimal contract at $t=2$, the amount the borrower repays in consumption goods in the low state, $r_{1 L}^{*}(a)$, can be thought of as the repayment of riskless debt at zero interest rate. The remaining part of the loan amount, $q_{1}^{c}(a)=q_{1}^{*}(a)-r_{1 L}^{*}(a)$, is repaid in consumption goods only if the return of the project is high, whereas if the return is low, the lender receives $a$ units of the asset from the borrower. Therefore, $q_{1}^{c}(a)$ can be interpreted as a loan collateralized by $a$ units of the asset at an interest rate of:

$$
i^{c}=\frac{r_{1 H}^{*}(a)-r_{1 L}^{*}(a)}{q_{1}^{c}(a)}-1=\frac{\beta \pi_{L}\left(V_{2}^{B}(a)-V_{2}^{L}(a)\right)}{\left(d a+\beta V_{2}^{L}(a)\right)+\beta \pi_{H}\left(V_{2}^{B}(a)-V_{2}^{L}(a)\right)} .
$$

The higher the difference in asset valuations between the borrower and the lender, the higher the amount of consumption goods the borrower can credibly commit to repay in the high state by pledging his assets as collateral.

This implementation is the one with the maximum amount of collateralized debt. Then, the maximum amount that the borrower can obtain against one unit of the asset, its debt capacity, is given by:

$$
D=\underbrace{(1+\beta) d}_{\text {Insurance }}+\underbrace{\beta \pi_{H}\left(v_{2}^{B}-v_{2}^{L}\right)}_{\text {Incentives }},
$$

where $v_{2}^{B}$ and $v_{2}^{L}$ are the marginal valuations for the asset of the borrower and lender, respectively. ${ }^{10}$

The asset's debt capacity depends on its value as collateral for lenders when there is default (insurance) and on the extra value borrowers attach to the asset when there is no default (incentives). Ceteris paribus, a higher asset value for lenders increases the loan amount since it allows lenders to recover more in the event of default, while a higher (extra) asset value for borrowers decreases the borrower's incentives to report untruthfully and, therefore, allows them to borrow more against the asset.

Whenever the borrower values the asset higher than the lender, the borrower finds it less expensive to repay the lender in goods than in assets. In other words, whenever the marginal rate of substitution between assets and consumption goods is higher for the borrower than for the lender, transferring the asset is costly for the borrower and the borrower strictly prefers pledging the asset as collateral rather than selling it. The model in Section 3 emphasizes this result by considering the case in which an asset market may be available at the end of the first period.

\footnotetext{
${ }^{10}$ Since preferences are quasilinear in consumptino, the marginal valuations for the asset are also the marginal rate of substitution between the asset and consumption good.
} 
Collateral premium The borrower's value of holding $a$ units of the asset at $t=1, V_{1}^{B}(a)$, is greater that the value he would get it he sold the asset to invest in his project, i.e.,

$$
V_{1}^{B}(a)>\frac{\left(\mathbb{E}(\theta)-\theta_{L}\right)}{1-\theta_{L}}\left(d a+\beta V_{2}^{L}(a)\right) .
$$

The borrower gets an expected return on equity of $\frac{\left(\mathbb{E}(\theta)-\theta_{L}\right)}{1-\theta_{L}}$ per unit invested in his project. By setting $t_{1 L}=t_{1 H}=a$, the borrower can sell the asset to the lender at $t=1$ in exchange for the lender's valuation, $d a+\beta V_{2}^{L}(a)$. Therefore, asset sales allow the borrower to invest $\frac{d a+\beta V_{2}^{L}(a)}{1-\theta_{L}}$ in his project. By pledging the asset as collateral, the borrower is able to invest an additional amount, $\Delta q^{*}$. Thus, when the borrower is able to use the asset as collateral, he attaches an additional value to it on top the asset's sale value $\frac{\left(\mathbb{E}(\theta)-\theta_{L}\right)}{1-\theta_{L}}\left(d a+\beta V_{2}^{L}(a)\right)$. The collateral premium is the expected return on equity of the additional amount the borrower can get from the lender by pledging the asset as collateral instead of selling it. The collateral premium is defined as follows:

$$
V_{1}^{B}(a)-\frac{\left(\mathbb{E}(\theta)-\theta_{L}\right)}{1-\theta_{L}}\left(d a+\beta V_{2}^{L}(a)\right)=\frac{\left(\mathbb{E}(\theta)-\theta_{L}\right)}{1-\theta_{L}} \Delta q^{*}
$$

The collateral premium further increases the difference in valuations between the borrower and the lender and, as can be seen in the dynamic model in the extensions, it is a key determinant of the asset's debt capacity.

\section{Market for the asset}

In the baseline model, it is crucial for the borrower and the lender to value the asset differently in order for the borrower to strictly prefer to use the asset as collateral. This difference in marginal rates of substitutions between assets and consumption goods, which is at the center of the main result, depends on how easy it is for the borrower and the lender to transform consumption goods into assets and vice-versa at the end of the first period. The model presented in this section extends the baseline model to consider the case in which, with certain probability, the borrower and the lender are able to access a competitive asset market. The asset's market liquidity, that is, the probability with which this market is available, is a crucial determinant of the marginal valuations for the asset and of the funding liquidity and collateral premia.

The model is the same as the baseline two-period model described in Section 2 except that, with probability $\alpha$, at the end of $t=1$ a continuum of ex-ante identical borrowers and lenders can trade in a competitive asset market. As in the baseline model, at $t=2$ borrowers are indifferent 
between selling their assets or pledging them as collateral. Thus, a borrower's valuation for $a$ units of the asset at the beginning of $t=2$ is:

$$
V_{2}^{B}(a)=\frac{\mathbb{E}(\theta)-\theta}{1-\theta_{L}} d a
$$

while a lender values $a$ units of the asset $V_{2}^{L}(a)=d a$.

\subsection{Asset market}

If the asset market is open at the end of $t=1$, which occurs with probability $\alpha$, a borrower with assets $a$ and wealth $w$ will buy $x$ units of the asset to solve the following problem:

$$
V^{m k t}(a, w)=\max _{x} \beta V_{2}^{B}(a+x)+w-p x,
$$

subject to

$$
\begin{aligned}
p x & \leq w \\
x & \geq-a,
\end{aligned}
$$

where $p$ is the price in of the asset in terms of consumption good. The first constraint above is the borrower's budget constraint: he cannot pay more for his purchases than the resources he has. The second constraint above implies that the borrower cannot sell more units of the asset than the ones he owns. The wealth level $w$ is the residual project return after paying the lender.

A borrower with assets $a$ and wealth $w$ has a demand for the asset given by:

$$
x^{B}(a, w)=\left\{\begin{array}{ll}
-a & \text { if } p>\beta v_{2}^{B} \\
\in\left[-a, \frac{w}{p}\right] & \text { if } p=\beta v_{2}^{B} \\
\frac{w}{p} & \text { if } p<\beta v_{2}^{B}
\end{array} .\right.
$$

Given the linear structure of the problem in (1), a borrower will $(i)$ sell all of his assets if the asset price $p$ is above his marginal valuation for the asset, $(i i)$ he will buy as many assets as he can if his marginal valuation for the asset is greater than the price, and (iii) he will be indifferent between buying or selling otherwise.

If the aggregate assets held by borrowers are $\bar{a}_{B}$ and their aggregate wealth is $\bar{w}_{B}$, the borrowers' aggregate demand in the asset market is:

$$
X^{B}\left(\bar{a}_{B}, \bar{w}_{B}\right)=\left\{\begin{array}{ll}
-\bar{a}_{B} & \text { if } p>\beta v_{2}^{B} \\
\in\left[-\bar{a}_{B}, \frac{\bar{w}_{B}}{p}\right] & \text { if } p=\beta v_{2}^{B} \\
\frac{\bar{w}_{B}}{p} & \text { if } p<\beta v_{2}^{B}
\end{array} .\right.
$$


Similarly, a lender with assets $a$ and wealth $w$ has a demand for the asset given by:

$$
x^{L}= \begin{cases}-a & \text { if } p>\beta v_{2}^{L} \\ \in\left[-a, \frac{w}{p}\right] & \text { if } p=\beta v_{2}^{L} \\ \frac{w}{p} & \text { if } p<\beta v_{2}^{L}\end{cases}
$$

and the lenders' aggregate demand in the asset market is:

$$
X^{L}\left(\bar{a}_{L}, \bar{w}_{L}\right)=\left\{\begin{array}{ll}
-\bar{a}_{L} & \text { if } p>\beta v_{2}^{L} \\
\in\left[-\bar{a}_{L}, \frac{\bar{w}_{L}}{p}\right] & \text { if } p=\beta v_{2}^{L} \\
\frac{\bar{w}_{L}}{p} & \text { if } p<\beta v_{2}^{L}
\end{array},\right.
$$

where $\bar{a}_{L}$ are the lenders' aggregate asset holdings and $\bar{w}_{L}$ is their aggregate wealth.

Since $v_{2}^{B}>v_{2}^{L}$, borrowers are buyers in the asset market and lenders are sellers. And since there is a fixed supply of assets and a fixed supply of goods, the price in the competitive asset market is determined by cash-in-the-market pricing. Thus, the equilibrium asset price $p^{*}$ is given by:

$$
p^{*}=\max \left\{\beta v_{2}^{L}, \min \left\{\frac{\bar{w}_{B}}{\bar{a}_{L}}, \beta v_{2}^{B}\right\}\right\} .
$$

The price $p^{*}$ depends on the liquidity available in the asset market, i.e., on the ratio between the available consumption goods held by the borrowers (buyers) and the available assets held by the lenders (sellers). The higher this ratio, the higher the price $p^{*}$.

Finally, if the asset market is open, the value of holding $a$ units of the asset and wealth $w$ for a borrower is:

$$
V^{m k t}(a, w)=\beta V_{2}^{B}\left(a+\frac{w}{p^{*}}\right)
$$

while the value of a lender is $p^{*} a+w$.

Remark. The asset market structure described above can also be interpreted as the result of a market in which there are search or matching frictions, as follows. Let $\alpha$ be the probability with which a borrower and a lender meet. Upon meeting, the terms of trade between them are determined through Nash bargaining, where the bargaining power of the borrower is $\gamma \in[0,1]$. This market structure and the competitive one described above are isomorphic if the bargaining power of the lender and the borrower is chosen appropriately. More specifically, if the bargaining power of the borrower is set to:

$$
\gamma=\frac{\beta v_{2}^{B}-p^{*}}{\beta\left(v_{2}^{B}-v_{2}^{L}\right)} .
$$




\section{$3.2 \quad$ Funding market}

At $t=1$, the borrower chooses his funding contract, taking into account that with probability $\alpha$ he will be able to use the proceeds from his project to purchase assets in the asset market 11 Let $w_{i} \equiv \theta_{i} q-r_{i}+d\left(a-t_{i}\right)$ be the borrower's wealth at the end of $t=1$ in state $i$. A borrower with assets $a$ solves the following problem:

$$
\begin{gathered}
\max _{q, r_{L}, r_{H} \cdot t_{L}, t_{H}}(1-\alpha)\left(\pi_{H}\left(w_{H}+\beta V_{2}^{B}\left(a-t_{H}\right)\right)+\pi_{L}\left(w_{L}+\beta V_{2}^{B}\left(a-t_{L}\right)\right)\right) \\
+\alpha\left(\pi_{H} V^{m k t}\left(a-t_{H}, w_{H}\right)+\pi_{L} V^{m k t}\left(a-t_{L}, w_{L}\right)\right)
\end{gathered}
$$

subject to the feasibility constraints in equation (2), the incentive compatibility constraint in the high state:

$$
\begin{aligned}
& (1-\alpha)\left(w_{H}+\beta V_{2}^{B}\left(a-t_{H}\right)\right)+\alpha V^{m k t}\left(a-t_{H}, w_{H}\right) \\
\geq & (1-\alpha)\left(w_{L}+\left(\theta_{H}-\theta_{L}\right) q+\beta V_{2}^{B}\left(a-t_{L}\right)\right)+\alpha V^{m k t}\left(a-t_{L}, w_{L}+\left(\theta_{H}-\theta_{L}\right) q\right),
\end{aligned}
$$

the incentive compatibility constraint in the low state if lying is feasible, i.e., if $r_{H} \leq \theta_{L} q+d\left(a-t_{L}\right)$,

$$
\begin{aligned}
& (1-\alpha)\left(w_{L}+\beta V_{2}^{B}\left(a-t_{L}\right)\right)+\alpha V^{m k t}\left(a-t_{L}, w_{L}\right) \\
\geq & (1-\alpha)\left(w_{H}+\left(\theta_{L}-\theta_{H}\right) q+\beta V_{2}^{B}\left(a-t_{H}\right)\right)+\alpha V^{m k t}\left(a-t_{H}, w_{H}+\left(\theta_{L}-\theta_{H}\right) q\right),
\end{aligned}
$$

and the lender's participation constraint:

$$
q \leq \pi_{H}\left(r_{H}+d t_{H}\right)+\pi_{L}\left(r_{L}+d t_{L}\right)+\beta\left(\pi_{H} \hat{V}_{2}^{L}\left(t_{H}\right) t_{H}+\pi_{L} \hat{V}_{2}^{L}\left(t_{L}\right) t_{L}\right)
$$

where

$$
\hat{V}_{2}^{L}(a)=\left((1-\alpha) d+\alpha \frac{p^{*}}{\beta}\right) a,
$$

is the expected value of holding $a$ units of the asset at the end of $t=1$ for the lender in terms of $t=2$ consumption.

The solution to the borrower's problem stated above leads to the following proposition:

Proposition 3 Borrowers strictly prefer to pledge the asset as collateral rather than selling it if and only if $\alpha \in[0,1)$. If $\alpha=1$, borrowers are indifferent between the two options.

When the asset market is not available at the end of $t=1$, i.e., $\alpha=0$, the borrower prefers to pay the lender in terms of consumption good rather than in assets. In this case, as in the

\footnotetext{
${ }^{11}$ For simplicity, the funding contract cannot be contingent on whether the asset market is open.
} 
baseline model, the marginal rate of substitution between assets and consumption goods differs for borrowers and lenders. For each unit of the asset the borrower transfers to the lender, the lender is willing to increase the loan size by $v_{2}^{L}$. This transfer costs the borrower $v_{2}^{B}$. Alternatively, the borrower could get the lender to increase the size of the loan in $v_{2}^{L}$ by transferring $v_{2}^{L}$ units of consumption good, which would cost him only $v_{2}^{L}$. Since $v_{2}^{L}<v_{2}^{B}$, it is less costly for the borrower to pay the lender in consumption goods than to pay him in terms of assets.

If the asset market is always available at the end of $t=1$, i.e., $\alpha=1$, the borrower is indifferent between repaying the lender in terms of assets or consumption goods. For each unit of the asset he gives the lender, the lender is willing to increase the size of the loan in $p^{*}$. Alternatively, the borrower could attain the same increase in loan size by transferring $p^{*}$ units of consumption good to the lender. However, the borrower's opportunity cost of this transfer is not being able to buy one unit of the asset in the market.

When the asset market is randomly available, i.e., $\alpha \in(0,1)$, in expectation it is less costly for the borrower to repay the lender in consumption goods than in assets. In other words, transferring the asset to the lender is costly for the borrower in expectation. Analogously to the baseline model, whenever transferring the asset to the lender is costly for the borrower, the borrower strictly prefers to pledge the asset as collateral and only transfer it to the lender if he cannot remit compensation in consumption goods.

\subsection{Premia and liquidity}

The ease with which an asset can be traded, that is, its market liquidity, is a key determinant of the equilibrium valuations for borrowers and lenders. In the model described in this section, the asset is perfectly liquid at the beginning of each period $t$ since the borrower can always sell the asset to the lender by setting $t_{L}=t_{H}$. The asset's market liquidity at the end of the first period depends on the likelihood of the asset market being open, i.e., on the parameter $\alpha$. The higher the probability that the asset market will open at the end of $t=1$, the higher the asset's market liquidity in the future.

Definition 4 An asset's market liquidity is determined by the likelihood with which it can be traded at $t=1$, i.e., by the parameter $\alpha$.

The parameter $\alpha$, which from now on I will refer to as the asset's market liquidity, affects the borrowers' and lenders' valuation for the asset and, through them, the (funding) liquidity and 
collateral premia.

The value a borrower assigns to selling the asset to raise funds, the asset's sale value, is given by:

$$
\frac{\mathbb{E}(\theta)-\theta_{L}}{1-\theta_{L}}\left(1+\alpha\left(\frac{\beta v_{2}^{B}}{p^{*}}-1\right)\right)\left(d+\beta \hat{v}_{2}^{L}\right) a,
$$

where $\left(1+\alpha\left(\frac{\beta v_{2}^{B}}{p^{*}}-1\right)\right)$ is the borrower's expected marginal value of a unit of consumption good at the end of the first period before he knows whether the asset market is open.

The value a borrower assigns to using the asset as collateral, the asset's collateral value, is:

$$
\text { Sale value }+\frac{\mathbb{E}(\theta)-\theta_{L}}{1-\theta_{L}} \beta \pi_{H}\left(v_{2}^{B}-\left(1+\alpha\left(\frac{\beta v_{2}^{B}}{p^{*}}-1\right)\right) \hat{v}_{2}^{L}\right)
$$

In this model, I define the liquidity and collateral premia as in the baseline model. The liquidity premium is the difference between the sale value of the asset and its fundamental value, i.e., the sum of its discounted dividends. The collateral premium is the difference between the collateral value of the asset and its sale value.

As the following proposition shows, the asset's liquidity affects the liquidity and collateral premia in opposite ways.

Proposition 4 An increase in the asset's liquidity at the end of the first period, i.e., an increase in $\alpha:$ a) Increases the funding liquidity premium, and b) decreases the collateral premium.

An increase in the asset's liquidity increases the borrower's sale value of the asset through two channels. First, a higher $\alpha$ increases the probability a lender gets a price $p^{*} \geq \frac{d}{\beta}$ for the asset at the end of the first period. This (weakly) increases the lender's valuation of the asset and, in turn, the amount the borrower can obtain from the sale of the asset. Second, by increasing the probability with which a borrower can use the proceeds of his investment to buy assets, it increases the borrower's value of holding funds at the beginning of the first period. These two channels imply a higher liquidity premium since they lead to a higher difference between the sale value of the asset and its fundamental value.

On the other hand, an increase in the asset's liquidity decreases its collateral premium since it decreases the difference in the marginal rates of substitutions between assets and consumption goods for both borrowers and lenders, i.e., it decreases $v_{2}^{B}-\left(1+\alpha\left(\frac{\beta v_{2}^{B}}{p^{*}}-1\right)\right) \hat{v}_{2}^{L}$. The lower this difference, the less costly it is for the borrower to transfer the asset to the lender and the lower the additional value the borrower attaches to being able to use the asset as collateral. Figure 2 illustrates these results. 


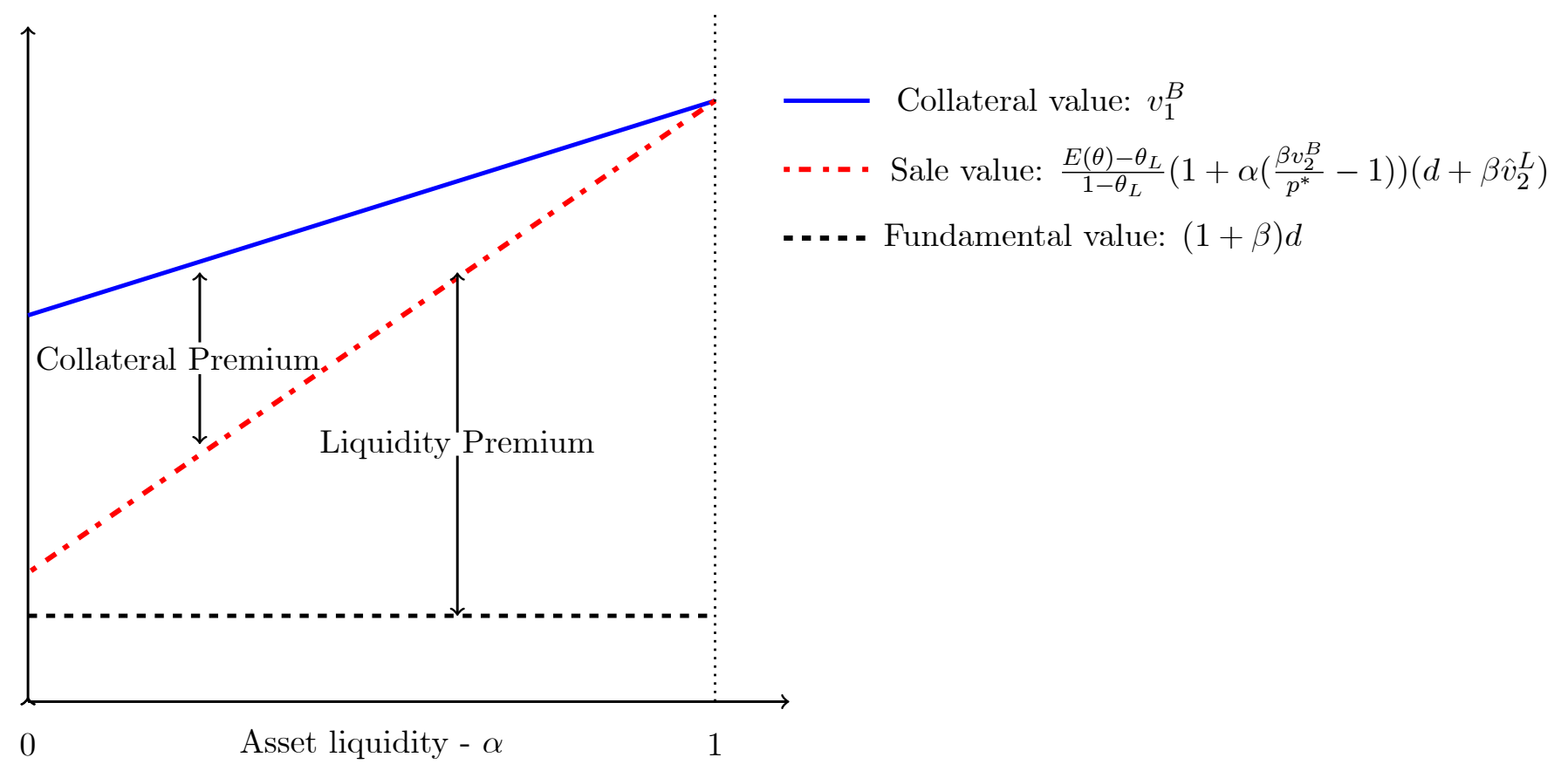

Figure 2: Asset liquidity and premia

Remark. The liquidity of the asset at the end of the first period depends on $\alpha$. However, as mentioned above, the asset is perfectly liquid at the beginning of the period since the borrower can always choose to sell his assets to the lender by setting $t_{L}=t_{H}=a$. As illustrated in this section, the borrower will choose to pledge his liquid financial asset to raise funds as long as the asset is not perfectly liquid at the end of the period.

Assuming $\alpha<1$ implies that there is a state of the world in which the asset is illiquid and there is no market in which it can be traded. This is a reasonable assumption given the evidence of market freezes. Market freezes were recurrent during the last financial crisis. However, they can also occur in less extreme situations even in markets for the most liquid assets. For example, in July 2015, U.S. Treasury debt, which is widely used as collateral in repo markets, became increasingly harder to trade in response to binding capital constraints faced by banks. According to the Financial Times, "banks pulled back from quoting prices, while other traders reduced their presence during the most extreme moments of turmoil, impairing the ability of investors to transact cash bonds." Similarly, the liquidity in the U.S. Treasury debt market decreased notably in 2013 in anticipation 
of the tapering of the Federal Reserve's quantitative easing policy ${ }^{12}$

More generally, any transaction cost or friction that imposes a wedge in the marginal rates of substitution between assets and consumption goods for the borrower and the lender will lead to the borrower strictly preferring to use the asset as collateral rather than selling it.

\section{Long-term contract}

So far, I have restricted the set of contracts to short-term contracts. In this section, I show that focusing on short-term contracts is without loss of generality because the sequence of optimal short-term contracts in the baseline model implements the long-term contract that satisfies the participation constraints for the lender in periods 1 and 2.

Definition 5 (Long-term Contract) A long-term contract $\psi$ consists of:

1. A loan amount in period $1, q$.

2. Loan amounts in period 2 contingent on the report in period $1, q_{L}$ and $q_{H}$.

3. Repayments in terms of the consumption good

in period 1, contingent on the report in period $1, r_{L}$ and $r_{H}$

in period 2 , contingent on the reports in periods 1 and $2, r_{L L}, r_{L H}, r_{H L}$, and $r_{H H}$.

4. Repayments in terms of assets

in period 1 , contingent on the report in period $1, t_{L}$ and $t_{H}$

in period 2 , contingent on the report in periods 1 and $2, t_{L L}, t_{L H}, t_{H L}$, and $t_{H H}$.

As in the case of the short-term contract, in equilibrium a long-term contract has to be feasible and incentive compatible. These conditions are expressed in the following borrower's problem as constraints $1-3$. Finally, I assume that the lender can walk away from the contract at any time and, therefore, his participation constraints have to be satisfied in periods 1 and 2 . These are constraints 4 and 5 below. The borrower chooses a long-term contract to maximize his expected utility:

$$
\begin{aligned}
\max _{\psi} & \mathbb{E}(\theta) q-\pi_{L}\left(r_{L}+d t_{L}\right)-\pi_{H}\left(r_{H}+d t_{H}\right)+(1+\beta) d a \\
& +\beta \sum_{i=L, H} \pi_{i}\left(\mathbb{E}(\theta) q_{i}-\pi_{L}\left(r_{i L}+d t_{i L}\right)-\pi_{H}\left(r_{i H}+d t_{i H}\right)-d t_{i}\right)
\end{aligned}
$$

\footnotetext{
${ }^{12}$ See "U.S. Treasuries market faces liquidity concerns", Financial Times, July 29, 2015 and "Liquidity deteriorates for U.S. Treasuries", Financial Times, November 23, 2015. Retrieved from http://www.ft.com/. Last accessed April 1st, 2016.
} 
subject to:

1. Feasibility constraints at $t=1$ and $t=2$.

2. Incentive compatibility constraints at $t=1$ :

$$
\begin{aligned}
& -r_{L}-d t_{L}+\beta\left(\mathbb{E}(\theta) q_{L}-d t_{L}-\pi_{L}\left(r_{L L}+d t_{L L}\right)-\pi_{H}\left(r_{L H}+d_{t H}\right)\right) \\
= & -r_{H}-d t_{H}+\beta\left(\mathbb{E}(\theta) q_{H}-d t_{H}-\pi_{L}\left(r_{H L}+d t_{H L}\right)-\pi_{H}\left(r_{H H}+d t_{H H}\right)\right) .
\end{aligned}
$$

3. Incentive compatibility constraints at $t=2^{13}$,

$$
r_{i L}+d t_{i L}=r_{i H}+d t_{i H}, i=L, H .
$$

4. Participation constraint for the lender at $t=1$ :

$$
\begin{aligned}
q+\beta\left(\pi_{L} q_{L}+\pi_{H} q_{H}\right) \leq & \pi_{L}\left(r_{L}+d t_{L}\right)+\pi_{H}\left(r_{H}+d t_{H}\right) \\
& +\beta \sum_{i=L, H} \pi_{i}\left(d t_{i}+\pi_{L}\left(r_{i L}+d t_{i L}\right)+\pi_{H}\left(r_{i H}+d t_{i H}\right)\right) .
\end{aligned}
$$

5. Participation constraint for the lender at $t=2$ :

$$
q_{i} \leq \pi_{L}\left(r_{i L}+d t_{i L}\right)+\pi_{H}\left(r_{i H}+d t_{i H}\right), i=L, H
$$

In contrast to the case in which only short-term contracts are allowed, using long-term contracts allows the borrower to directly contract on the loan amounts at $t=2$. However, since these amounts depend on the resources that can be pledged at $t=2$ through the feasibility and incentive compatibility constraints, asset transfers are a way of indirectly contracting on loan amounts. In fact, the optimal long-term contract can be implemented by a series of short-term contracts.

Proposition 5 The optimal short-term contracts implement the optimal long-term contract.

The proof follows directly from the characterization of the optimal long-term contract in the Appendix.

The second-best long-term contract, the contract that ignores the participation constraints for the lender in period 2, implies $q_{H}>\pi_{L} r_{H L}+\pi_{L} r_{H H}$ and $r_{H}>r_{H}^{* *}$. Since the borrower cannot commit to repay more than $\theta_{L} q_{i}+d a$ in the second period, he would like to pre-pay the lender for a

\footnotetext{
${ }^{13}$ Risk neutrality implies that the incentive compatibility constraints at $t=1$ and $t=2$ can be expressed as one constraint, as stated in points 2 and 3 .
} 
higher loan at $t=2$. This higher loan at $t=2$ also imposes a higher penalty for lying and therefore increases the initial loan amount $q$. However, lenders would never be able to credibly agree to this contract if they could walk away from it.

Remark. The optimal contract described here resembles the optimal contract in Bolton and Scharfstein (1990). However, there are key differences between the assumptions and results in their paper and the ones presented here. In this paper the presence of a long-lived financial asset allows for lending to occur with short-term contracts. In fact, the existence of a long-lived financial assets implies that a sequence of short-term contracts can achieve the same allocation as the optimal long-term contract which, as in Bolton and Scharfstein (1990), involves the firm not being operated if the low state is realized. Moreover, in Bolton and Scharfstein (1990), the firm itself is pledged as collateral by allowing it to be liquidated in the event of a bad report. Therefore, the asset used as collateral is needed in order for the firm to operate and, thus, cannot be sold if it wants to continue operating. In my model, the project available to the borrower are inalienable and the financial asset that is used as collateral in equilibrium is unrelated to the operations of the firm. This implies that the borrower can choose to sell his assets and still be able to invest in his project, which is crucial to answer why assets are used as collateral instead of being sold to raise funds.

\section{Extensions}

In this section, I present several extensions to show the robustness of the main result and the economic intuition behind it. All the extensions are departures from the baseline model presented in Section 2 in which the funding contract is restricted to a short-term contract. First, I consider risky long-term assets and allow the asset's dividends and the project's returns to be correlated. Second, I allow for stochastic investment opportunities. This extension highlights the role that the persistence in the roles as borrower and lender play in the main result. Finally, I introduce a fully dynamic infinite horizon model.

\subsection{Correlated dividends and returns}

In the baseline model I assumed the financial asset was riskless. However, many risky assets are used as collateral in financial transactions. For example, mortgage back securities (MBS) were massively used as collateral to finance new mortgages or real estate related securities at the onset of the 2008 - 2009 financial crisis. This extension allows for risky financial assets whose dividends 
may be correlated with the returns of the project operated by the borrower. I show that, consistent with the widely spread use of MBS as collateral, assets with payoffs highly correlated with the investment opportunity are better collateral.

Consider the baseline model presented in Section 2 with the only difference being that the asset's dividend is stochastic and it is potentially correlated with the return of the borrower's risky project. Although the dividends are paid at the end of each period, after the borrower invests in his risky project, they are known at the beginning of each period. This implies that there is only uncertainty about the dividend paid by the asset in the second period. The asset's dividend distribution is such that:

$$
\mathbb{E}\left(d_{2} \mid \theta_{1}=\theta_{i}\right)=d_{i}, \text { for } i=L, H,
$$

and

$$
\mathbb{E}\left(d_{2}\right)=\pi_{H} d_{H}+\pi_{L} d_{L}=\bar{d}
$$

Given a dividend $d_{2}$ at $t=2$, the borrower's problem in the second period remains the same. The value of a borrower who holds $a$ units of the asset at the beginning of the second period is:

$$
V_{2}^{B}\left(a, d_{2}\right)=\frac{\mathbb{E}(\theta)-\theta_{L}}{1-\theta_{L}} d_{2} a
$$

Analogously, the value for the lender of holding $a$ units of the asset at the beginning of the second period is:

$$
V_{2}^{L}\left(a, d_{2}\right)=d_{2} a
$$

Given that the value functions for the borrower and the lender are linear in the dividend level, it is easy to see that all the results in the baseline model generalize to this extension. In particular, the asset's debt capacity becomes:

$$
D=d_{1}+\beta \bar{d}+\beta \pi_{H}\left(\frac{V_{2}^{B}\left(a, d_{H}\right)}{a}-\frac{V_{2}^{L}\left(a, d_{H}\right)}{a}\right) .
$$

The following proposition shows that assets with dividends that are more highly positively correlated with the borrower's project are better collateral.

Proposition 6 Assets that have dividends that are more highly positively correlated with the risky project have a higher debt capacity, i.e.,

$$
\frac{\partial D}{\left.\partial d_{H}\right|_{\bar{d}}}>0
$$


In the model, the financial asset partly resolves the non-contractibility of the return on the risky project by allowing the borrower to raise funds. Since in equilibrium the borrower values the asset more than the lender does, $V_{2}^{B}\left(a, d_{H}\right)-V_{2}^{L}\left(a, d_{H}\right)$ is the endogenous cost of defaulting on the promised amount, $r_{H}-r_{L}$, which allows the borrower to credibly commit to truthfully reporting the project's return. An asset that has dividends that are more highly positively correlated with the return of the risky project has a higher $d_{H}$, which implies a higher cost of default for borrowers. This higher cost of default allows the borrower to commit a larger amount of consumption goods in the high state and, thus, increases the debt capacity of the asset, which makes it better collateral.

\subsection{Stochastic investment opportunities}

In the baseline model, I assume that a borrower always has access to an investment opportunity while a lender can never invest in it directly. This assumption can be relaxed to allow for probabilistic access to the risky project. Doing so emphasizes the importance of the persistence of the investment opportunities discussed for the baseline model in Section 2 .

The next model is the same as the baseline model with the exception that now the borrower remains a borrower (and the lender remains a lender) with probability $\rho$. An agent who has a borrowing opportunity in the first periods keeps his investment opportunity in the second period with probability $\rho$ while an agent without a lending opportunity in the first period acquires one in the second period with probability $(1-\rho)$. Whether an agent has access to an investment opportunity or not in a certain period is known at the beginning of that period. Agents who are endowed with an investment opportunity do not get any endowment of the consumption good.

The only difference between the borrower's and lender's problems in this setup and those in the baseline model is in the continuation values they face in the first period. In the baseline model, each agent knows in which side of the market he will participate next; in the current model, their role in the economy is random. Therefore, everything derived in the baseline model holds by substituting $V_{2}^{B}(a)$ by:

$$
\rho V_{2}^{B}(a)+(1-\rho) V_{2}^{L}(a)
$$

and $V_{2}^{L}(a)$ by:

$$
\rho V_{2}^{L}(a)+(1-\rho) V_{2}^{B}(a)
$$

Analogous to the baseline case, a borrower will only choose to transfer the asset in the high state if the lender values the asset at least as much as he does. The next proposition formalizes 
this finding.

Proposition 7 The borrower will strictly prefer to use the asset as collateral if and only if investment opportunities are persistent, i.e., if $\rho>0.5$.

Since having the asset is more valuable while having access to an investment opportunity, the borrower will value the asset more than lender only if his likelihood of being a borrower the next period is higher than the lender's. Therefore, as long as the investment opportunities are persistent, the borrower will always choose to use the asset as collateral rather than selling it.

Suppose that $\rho>0.5$. Then, the debt capacity of the asset is given by:

$$
D=d+\beta\left(\rho v_{2}^{L}+(1-\rho) v_{2}^{B}\right)+\beta \pi_{H}(2 \rho-1)\left(v_{2}^{B}-v_{2}^{L}\right) .
$$

As in the baseline case, the debt capacity has two components: one that provides insurance to the lender and one that provides incentives to the borrower. The lender is always willing to lend his own valuation for the asset, $d+\beta\left(\rho v_{2}^{L}+(1-\rho) v_{2}^{B}\right)$, if the loan is collateralized. The lender knows that defaulting is costly for the borrower. He also knows that the borrower has incentives to pay more in the high state to avoid losing the asset. Thus, the extra amount that the borrower is willing to pay in the high state is $\beta(2 \rho-1)\left(v_{2}^{B}-v_{2}^{L}\right)$.

\subsection{Dynamic model}

I extend the baseline model to an infinite horizon model. By taking into account the feedback of future collateral premia on the current collateral value of an asset, it allows me to show that longer-lived assets are better collateral.

In the infinite horizon model, time is discrete and goes on forever. There are two risk-neutral agents, a borrower and a lender, with the same endowments as the ones described for the baseline model in Section 2. In fact, each period $t$ is exactly the same as the one described in Figure 1.

Assumption 2 (Impatience dynamic) The discount factor $\beta$ satisfies $\beta \frac{\mathbb{E}(\theta)-\theta_{L}}{1-\theta_{L}}<1$.

Analogous to Assumption 1 in the baseline model, Assumption 2 implies that the borrower will always choose to consume consumption goods rather than saving them. Therefore, I can ignore the borrower's saving decision. Moreover, if Assumption 2 does not hold, the borrower always chooses to postpone consumption to the following period, which, in the context of an infinite horizon model, implies he never consumes while getting an infinite value from doing so. 
Since the amount of asset in the hands of the borrower and the lender may change over time, the aggregate state variable of the economy is given by the distribution of the asset in the hands of borrowers and lenders. Let $V^{B}\left(a_{B}, a_{L}\right)$ and $V^{L}\left(a_{B}, a_{L}\right)$ be the value functions for the borrower and lender, respectively, when the borrower has $a_{B}$ units of the asset and the lender has $a_{L}$ units of the asset. The borrower's problem becomes:

$$
\begin{aligned}
V^{B}\left(a_{B}, a_{L}\right)= & \sup _{q, r_{L}, r_{H}, t_{H}, t_{L}} \mathbb{E}(\theta) q-\pi_{H}\left(r_{H}+d t_{H}\right)-\pi_{L}\left(r_{L}+d t_{L}\right)+d a_{B} \\
& +\beta \pi_{H} V^{B}\left(a_{B}-t_{H}, a_{L}+t_{H}\right)+\beta \pi_{L} V^{B}\left(a_{B}-t_{L} ; a_{L}+t_{L}\right),
\end{aligned}
$$

subject to the funding contract $\left(q, r_{L}, r_{H}, t_{L}, t_{H}\right)$ being feasible and incentive compatible, and satisfying the lender's participation constraint:

$$
\begin{aligned}
q+\beta V^{L}\left(a_{L}, a_{B}\right) \leq & \pi_{H} r_{H}+\beta \pi_{H} V^{L}\left(a_{L}+t_{H}, a_{B}-t_{H}\right) \\
& +\pi_{L} r_{L}+\beta \pi_{L} V^{L}\left(a_{L}+t_{L}, a_{B}-t_{L}\right) .
\end{aligned}
$$

Since the borrower has all bargaining power in the funding market,

$$
V^{L}\left(a_{L}, a_{B}\right)=\frac{d}{1-\beta} a_{L}
$$

Since $V^{L}\left(a_{L}, a_{B}\right)$ is linear in $a_{L}$ and does not depend on $a_{B}$, the value function for the borrower at the beginning of each period only depends on his own asset holdings. Thus, in a slight abuse of notation, I denote the value functions for the borrower and lender as $V^{B}\left(a_{B}\right)$ and $V^{L}\left(a_{L}\right)$, respectively. Looking at the borrower's problem in equation (2), it is easy to see that the funding contract will not depend on the lender's asset holdings either.

Definition 6 A recursive equilibrium in this economy is a value function for the borrower, $V^{B}\left(a_{B}\right)$, and a value function for the lender, $V^{L}\left(a_{L}\right)$, and a funding contract

$$
\left\{q\left(a_{B}\right), r_{L}\left(a_{B}\right), r_{H}\left(a_{B}\right), t_{L}\left(a_{B}\right), t_{H}\left(a_{B}\right)\right\}
$$

such that 2 and 3 are satisfied.

I next focus on recursive affine equilibria, i.e., equilibria in which the value functions are affine in asset holdings. Within this class of equilibria, the equilibrium is unique. All omitted proofs are in the Appendix.

In an affine equilibrium,

$$
V^{L}(a)=v_{L} a, \text { and } V^{B}(a)=v_{B} a .
$$

The following Lemma characterizes the borrower's optimal contingent asset transfers. 
Lemma 2 In an affine equilibrium, a borrower will choose

$$
\begin{aligned}
& t_{L}=a_{B}, \text { and } \\
& t_{H}= \begin{cases}a_{B} & \text { if } v_{B}<v_{L} \\
x \text { for some } x \in\left[0, a_{B}\right] & \text { if } v_{B}=v_{L} \\
0 & \text { if } v_{L}<v_{B}\end{cases}
\end{aligned}
$$

If the borrower assigns the same value to the asset as the lender, he will set $t_{L}=t_{H}=a_{B}$ and "sell" the asset to the lender. In exchange, the lender will lend the borrower $v_{L}=v_{B}$, which is fair compensation from the borrower's perspective.

However, if the borrower assigns a higher value to the asset than the lender, he would be getting less than his valuation if he chose to sell the asset to the lender: the lender would still pay a price $v_{L}$ per unit where now $v_{L}<v_{B}$. In this case, the borrower will only transfer the asset if he cannot avoid it, i.e., if the low return is realized and he does not have enough resources to compensate the lender in consumption goods. Transferring the asset is costly for the borrower since he gets $v_{L}$ units for it while he values it $v_{B}>v_{L}$. This difference in valuation can be interpreted as the "punishment" for not being truthful, which induces truth telling and makes the state contingent contract incentive compatible.

The following proposition establishes the main result that liquid financial assets are used as collateral for the dynamic model.

Proposition 8 In the unique affine equilibrium the borrower strictly prefers to use the asset as collateral rather than selling it.

In equilibrium, the borrower assigns a higher value to the asset than the lender. Holding assets allows the borrower to take advantage of his profitable investment opportunity either by selling the assets, by pledging its dividends or by pledging the assets themselves. The lender, in contrast, can only consume the dividends or sell the asset in the asset market. $\mathbb{E}(\theta)>1$ implies that the borrower assigns a higher value to the asset than the lender. Since investment opportunities are persistent, the borrower will value the asset more than the lender in the future as well.

Analogous to the baseline model, whether the borrower strictly prefers to use the asset as collateral depends on the asset's market liquidity. The results obtained in Section 3 extend to the dynamic version of the model presented here. 


\subsubsection{Premia}

As in the baseline model, one can decompose the additional value the borrower attaches to the asset over its fundamental value in two premia: a funding liquidity premium and a collateral premium. The fundamental value of the infinitely-lived asset is $\frac{d}{1-\beta}$. If the borrower sells the asset to the lender at the beginning of the period, he gets $d+\beta c_{L}$ consumption goods. The borrower can lever up against this amount and then invests in his risky project. Therefore, the borrower expects a return $\frac{\mathbb{E}(\theta)-\theta_{L}}{1-\theta_{L}}$ on the the proceeds from the asset sale. This implies that the liquidity premium is:

$$
\frac{\mathbb{E}(\theta)-\theta_{L}}{1-\theta_{L}}\left(d+\beta c_{L}\right)-\left(\frac{d}{1-\beta}\right)=\frac{\mathbb{E}(\theta)-1}{1-\theta_{L}} \frac{d}{1-\beta}>0 .
$$

Analogously to the baseline two-period model, the funding liquidity premium is equal to the levered excess return times the fundamental value of the asset.

The marginal value the borrower attaches to using a unit of the asset as collateral is $v_{B}$. Then, the collateral premium is:

$$
v_{B}-\frac{\mathbb{E}(\theta)-\theta_{L}}{1-\theta_{L}}\left(d+\beta c_{L}\right)=\frac{\mathbb{E}(\theta)-\theta_{L}}{1-\theta_{L}} \Delta q^{*},
$$

where

$$
\Delta q^{*}=\beta \pi_{H}\left(v_{B}-v_{L}\right)
$$

is the extra amount of funds the borrower can raise by pledging the asset as collateral rather than selling it. As in the two-period model, this additional amount depends on the difference in valuations for the asset between the borrower and the lender. However, in the infinite horizon model, this difference in valuation incorporates not only the liquidity premium in the next period but also all future collateral premia. The following proposition formalizes this argument.

Proposition 9 The collateral premium of an infinitely-lived asset is larger than that of a two-period asset. More generally, the collateral premium is increasing in the duration of the asset.

If the borrower expects to use the asset as collateral in the future, he attaches a higher value to using it as collateral today. Giving up an infinitely-lived asset is costlier to the borrower than giving up an asset that only lives for one additional period. The cost of transferring the longer-lived asset includes, not only losing the asset's liquidity premium but also all future collateral premia, which are not part of the cost of transferring the shorter-term asset. This implies that the borrower can credibly commit to transfer more consumption goods to avoid losing the longer-lived asset than he is to avoid losing a shorter-term one. The longer the duration of the asset the higher the value of the asset as collateral and the higher its debt capacity. 


\section{Conclusion}

Why are liquid financial assets used as collateral instead of being sold to raise funds? I show that when the roles as borrowers and lenders are persistent, and the return on the risky project is noncontractible, a borrower chooses to collateralize liquidity to raise funds. For each unit of the asset the borrower gives the lender, the borrower receives the lender's valuation in consumption good. Since the borrower values the asset more than the lender, transferring the asset to the lender is costly for the borrower. Offering the asset as collateral allows the borrower to transfer the asset only if he does not have enough resources to repay the lender in consumption good and, therefore, the borrower prefers to collateralize his liquid assets rather than selling them.

This difference in asset valuations between the borrower and the lender is an equilibrium outcome. In autarky, both the borrower and the lender value the asset as the expected discounted sum of the asset's dividend stream. When the agents are able to trade, the borrower values the asset more than the lender and they both value the asset (weakly) more than its fundamental value. The borrower's excess valuation can be divided in two premia: a funding liquidity premium and a collateral premium. A crucial determinant of this valuation difference across agents is the asset's market liquidity. As long as the asset is not perfectly liquid in the future, the borrower and the lender value the asset differently and, thus, the borrower strictly prefers to use the asset as collateral rather than selling it. The liquidity and collateral premia are affected in different ways by the asset's liquidity. An increase in the likelihood of trading the asset, i.e., and increase in its liquidity, increases the liquidity premium while it decreases the collateral premium.

Changes in margins and haircuts played an important role in the recent crises (See Jermann and Quadrini (2012), Perri and Quadrini (2014)). Having a model that characterizes these objects as equilibrium outcomes is important both from a positive and a normative point of view. In positive terms, it is interesting to see where the financial shocks come from and how they interact with the economy's fundamentals. From the normative side, policies that aim at stabilizing the cycle and preventing financial crises should take into account what drives changes in the financing conditions faced by financial intermediaries, firms, and households. This paper delivers some of the insights needed to further understand collateralized debt markets. 


\section{Appendix}

This section contains all proofs omitted in the main text.

\subsection{Proof of Proposition 2}

This proposition is a special case of Proposition 11 in Subsection 7.3 when $\alpha=0$. All proofs omitted in Section 2 are special cases of the proofs in Subsection 7.3 when $\alpha=0$.

\subsection{Proof of Proposition 5}

The proof of this proposition follows directly from the characterization of the long-term contract in Proposition 10.

Proposition 10 In the optimal long-term contract $\phi^{*}$ :

1. The loan amounts are:

$$
\begin{aligned}
q^{* *} & =\left(1+\beta+\beta \pi_{H} \frac{(\mathbb{E}(\theta)-1)}{1-\theta_{L}}\right) \frac{d a}{1-\theta_{L}}, \\
q_{H}^{* *} & =\frac{d a}{1-\theta_{L}}, \quad \text { and } \quad q_{L}^{* *}=0 .
\end{aligned}
$$

2. Repayments in terms of consumption good are:

$$
\begin{aligned}
r_{L}^{* *} & =\theta_{L} q^{* *}, \quad r_{H}^{* *}=r_{L}^{* *}+d a+\beta \frac{(\mathbb{E}(\theta)-1)}{1-\theta_{L}} \frac{d a}{1-\theta_{L}}, \\
r_{2 L}^{* *} & =0, \quad \text { and } \quad r_{2 H}^{* *}=\theta_{L} q_{H}^{* *} .
\end{aligned}
$$

3. Asset transfers are:

$$
t_{L}^{* *}=a, \quad t_{H}^{* *}=0, \quad t_{2 L}^{* *}=0, \quad \text { and } \quad t_{2 H}^{* *}=a .
$$

Proof. Note that the participation constraints for the lender will hold with equality. Using the incentive compatibility constraints and the participation constraint in the first period, the objective function for the borrower becomes:

$$
(\mathbb{E}(\theta)-1)\left(r_{L}+d t_{L}+\beta\left(d t_{L}+r_{2 L}+d t_{2 L}\right)+\beta \pi_{H} \mathbb{E}(\theta)\left(\frac{d\left(t_{L}-t_{H}\right)}{1-\theta_{L}}\right)\right)+(1+\beta) d a .
$$

This implies:

$$
\begin{aligned}
t_{L}^{* *} & =a, \quad t_{H}^{* *}=0, \quad t_{2 L}^{* *}=0 \\
r_{2 L}^{* *} & =0, \quad \text { and } \quad r_{L}^{* *}=\theta_{L} q^{* *}
\end{aligned}
$$

Using these expressions in the participation and incentive compatibility constraints gives the contract in the proposition. 


\subsection{Proof of Proposition 3}

The proof of this proposition follows directly from Lemmas 5 and 6 in this section interpreting contingent asset transfers as collateralized debt and non-contingent ones as asset sales.

The borrower's problem in (1) can be considerably simplified by inspecting the constraints. First, in any equilibrium, the participation constraint for the lender will hold with equality. If it did not, the borrower could increase the loan amount and increase his expected utility without violating any of the additional constraints. Similarly, as is usual in this kind of problems, the incentive compatibility constraint will bind in the high state. Finally, in order to maximize the size of the loan, the repayment in terms of goods and assets in the low state, $r_{L}$ and $t_{L}$, will be the maximum possible, i.e., $r_{L}=\theta_{L} q$ and $t_{L}=a$. The Lemmas 3, 4, and 5 formalize these results.

Lemma 3 Without loss of generality, the lender's participation constraint can be replaced by:

$$
q=\pi_{H}\left(r_{H}+d t_{H}\right)+\pi_{L}\left(r_{L}+d t_{L}\right)+\beta\left(\pi_{H} \hat{V}_{2}^{L}\left(t_{H}\right)+\pi_{L} \hat{V}_{2}^{L}\left(t_{L}\right)\right)
$$

in the borrower's problem.

Proof. Since the objective function of the borrower is increasing in $q$, if the participation constraint does not hold with equality, the borrower can always improve on the contract by increasing the loan quantity $q$ and still satisfy all other constraints.

Lemma 4 Without loss of generality, the incentive compatibility constraint in the high state can be replaced by:

$(1-\alpha)\left(r_{H}+d t_{H}-\left(r_{L}+d t_{L}\right)\right)=\beta\left(V_{2}^{B}\left(a-t_{H}+\alpha \frac{\theta_{H} q-r_{H}+d\left(a-t_{H}\right)}{p^{*}}\right)-V_{2}^{B}\left(a-t_{L}+\alpha \frac{\theta_{H} q-r_{L}+d\left(a-t_{L}\right)}{p^{*}}\right)\right)$

in the borrower's problem.

Proof. Suppose that the incentive compatibility constraint does not hold with equality, i.e.,

$(1-\alpha)\left(r_{H}+d t_{H}-\left(r_{L}+d t_{L}\right)\right)<\beta\left(V_{2}^{B}\left(a-t_{H}+\alpha \frac{\theta_{H} q-r_{H}+d\left(a-t_{H}\right)}{p^{*}}\right)-V_{2}^{B}\left(a-t_{L}+\alpha \frac{\theta_{H} q-r_{L}+d\left(a-t_{L}\right)}{p^{*}}\right)\right)$.

Then, the borrower could increase $q, r_{H}$, and $r_{L}$ and increase the objective function while still satisfying all other constraints. In particular, there exists $\varepsilon_{0}, \varepsilon_{1}>0$ such that:

$$
\begin{aligned}
& (1-\alpha)\left(r_{H}+d t_{H}-\left(r_{L}+d t_{L}\right)+\left(\theta_{H}-\theta_{L}\right) \varepsilon_{0}\right) \\
\leq & \beta\left(V_{2}^{B}\left(a-t_{H}+\alpha \frac{-r_{H}+d\left(a-t_{H}\right)}{p^{*}}\right)-V_{2}^{B}\left(a-t_{L}+\alpha \frac{-r_{L}+d\left(a-t_{L}\right)}{p^{*}}\right)\right), \\
& (1-\alpha)\left(r_{L}+d t_{L}-\left(r_{H}+d t_{H}\right)-\left(\theta_{H}-\theta_{L}\right) \varepsilon_{0}\right) \\
\leq & \beta\left(V_{2}^{B}\left(a-t_{L}+\alpha \frac{-r_{L}+d\left(a-t_{L}\right)}{p^{*}}\right)-V_{2}^{B}\left(a-t_{L}+\alpha \frac{-r_{H}+d\left(a-t_{H}\right)}{p^{*}}\right)\right)
\end{aligned}
$$

and

$$
q+\varepsilon_{0}+\varepsilon_{1}=\pi_{H}\left(r_{H}+\theta_{H} \varepsilon_{0}+d t_{H}\right)+\pi_{L}\left(r_{L}+\theta_{L} \varepsilon_{0}+d t_{L}\right)+\beta\left(\pi_{H} \hat{V}_{2}^{L}\left(t_{H}\right)+\pi_{L} \hat{V}_{2}^{L}\left(t_{L}\right)\right) .
$$

Then, the contract $\left\{q+\varepsilon_{0}+\varepsilon_{1}, r_{L}+\theta_{L} \varepsilon_{0}, r_{H}+\theta_{H} \varepsilon_{0}, t_{L j}, t_{H j}\right\}$ satisfies the feasibility, participation and incentive compatibility constraints while attaining a higher asset value for the borrower.

In the next few pages, I will ignore the incentive compatibility constraint in the low state and then verify it is satisfied. 
Lemma 5 In the optimal contract, $r_{L}^{*}=\theta_{L} q$ and $t_{L}^{*}=a$.

Proof. Using Lemmas 3 , Lemma 4 and the linearity of $V_{2}$, the borrower's problem can be rewritten as:

$$
\begin{aligned}
& \max _{q, r_{H}, r_{L}, t_{H}, t_{L}}(1-\alpha)\left((\mathbb{E}(\theta)-1) q+\beta\left(\pi_{H} \hat{V}_{2}^{L}\left(t_{H}\right)+\pi_{L} \hat{V}_{2}^{L}\left(t_{L}\right)\right)+d a\right) \\
& +\beta V_{2}^{B}\left(a-t_{H}+\alpha \frac{\theta_{L} q-r_{H}+d\left(a-t_{H}\right)}{p^{*}}\right)+\pi_{L}(1-\alpha),
\end{aligned}
$$

subject to the feasibility constraints, the incentive compatibility constraint

$$
(1-\alpha)\left(r_{H}+d t_{H}-\left(r_{L}+d t_{L}\right)\right)=\beta\left(V_{2}^{B}\left(a-t_{H}+\alpha \frac{-r_{H}+d\left(a-t_{H}\right)}{p^{*}}\right)-V_{2}^{B}\left(a-t_{L}+\alpha \frac{-r_{L}+d\left(a-t_{L}\right)}{p^{*}}\right)\right),
$$

and the participation constraint for the lender

$$
\begin{aligned}
q= & \left(r_{L}+d t_{L}\right)+\beta\left(\pi_{H} \hat{V}_{2}^{L}\left(t_{H}\right)+\pi_{L} \hat{V}_{2}^{L}\left(t_{L}\right)\right) \\
& +\frac{\beta \pi_{H}}{1-\alpha}\left(V_{2}^{B}\left(a-t_{H}+\alpha \frac{\theta_{H} q-r_{H}+d\left(a-t_{H}\right)}{p^{*}}\right)-V_{2}^{B}\left(a-t_{L}+\alpha \frac{\theta_{H} q-r_{L}+d\left(a-t_{L}\right)}{p^{*}}\right)\right) .
\end{aligned}
$$

$q$ in the participation constraint of the lender and, thus, the objective function are increasing in $r_{L}$ and $t_{L}$. Moreover, increasing either $r_{L}$ or $t_{L}$ relaxes the incentive compatibility constraint in the high state. Therefore, any contract such that $r_{L}<\theta_{L} q$ or $t_{L}<a$ can be improved upon.

Lemma 6 In the optimal contract, $t_{H}=0$ as long as $\alpha \in[0,1)$ and If $\alpha=1, t_{H} \in[0, a]$.

Proof. From Lemma 5, we have $w_{L}=0$ and $t_{L}=a$. Then, the borrower's problem can be written as

$$
\max _{t_{H}}(1-\alpha) \pi_{H} w_{H}+\beta \pi_{H} V_{2}^{B}\left(a-t_{H}+\alpha \frac{w_{H}}{p^{*}}\right)
$$

where:

$$
w_{H}=\theta_{H} q-r_{H}+d\left(a-t_{H}\right),
$$

and $r_{H}$ and $q$ are respectively implicitly defined as a function of $t_{H}$ from the incentive compatibility constraint

$$
(1-\alpha)\left(\frac{r_{H}\left(1-\theta_{L}\right)+d t_{H}\left(1-\theta_{L}\right)-\theta_{L} \pi_{H} \beta \hat{v}_{2}^{L} t_{H}-\theta_{L} \pi_{L} \beta \hat{v}_{2}^{L} a-d a}{1-\pi_{L} \theta_{L}}\right)=\beta V_{2}^{B}\left(a-t_{H}+\alpha \frac{\theta_{L} q-r_{H}+d\left(a-t_{H}\right)}{p^{*}}\right)
$$

and the lender's participation constraint

$$
q=\frac{\pi_{H}\left(r_{H}+\left(d+\beta \hat{v}_{2}^{L}\right) t_{H}\right)+\pi_{L}\left(d+\beta \hat{v}_{2}^{L}\right) a}{1-\pi_{L} \theta_{L}} .
$$

The first order condition with respect to $t_{H}$ is:

$$
\pi_{H}\left((1-\alpha)+\alpha \frac{\beta v_{2}^{B}}{p^{*}}\right) \frac{d w_{H}}{d t_{H}}-\beta \pi_{H} v_{2}^{B},
$$


where:

$$
\begin{aligned}
\frac{d w_{H}}{d t_{H}} & =\frac{\partial w_{H}}{\partial r_{H}} \frac{\partial r_{H}}{\partial t_{H}}+\frac{\partial w_{H}}{\partial t_{H}} \\
& =-\frac{-\left((1-\alpha)\left(\mathbb{E}(\theta)-\theta_{L}\right)\left(1-\pi_{L} \theta_{L}\right)+\alpha \frac{\beta v_{2}^{B}}{p^{*}}\left(1-\theta_{L}\right) \pi_{H} \theta_{H}\right) \beta \hat{v}_{2}^{L}+(\mathbb{E}(\theta)-1) \beta v_{2}^{B}\left(1-\pi_{L} \theta_{L}-\alpha \pi_{H} \theta_{L} \frac{\beta \hat{v}_{2}^{L}}{p^{*}}\right)}{\left(1-\pi_{L} \theta_{L}\right)\left(1-\theta_{L}\right)\left((1-\alpha)+\alpha \frac{\beta v_{2}^{B}}{p^{*}}\right)},
\end{aligned}
$$

where I used the implicit function theorem, Eq. (4) and Eq. (5). Then, the first order condition in Eq. (6) becomes:

$$
\beta \pi_{H} \frac{\left(\mathbb{E}(\theta)-\theta_{L}\right)}{\left(1-\theta_{L}\right)}\left((1-\alpha)\left(\hat{d}-v_{2}^{B}\right)+\alpha V_{2}^{B \prime}\left(\frac{\beta \hat{v}_{2}^{L}}{p^{*}}-1\right)\right)
$$

For all $\alpha \in[0,1)$, the first order condition is negative since:

$$
\begin{aligned}
\hat{v}_{2}^{L}-v_{2}^{B} & =(1-\alpha)\left(d-v_{2}^{B}\right)+\alpha\left(\frac{p^{*}}{\beta}-v_{2}^{B}\right)<0, \text { and } \\
\frac{\beta \hat{v}_{2}^{L}}{p^{*}}-1 & =\frac{(1-\alpha) \beta d+\alpha p^{*}-p^{*}}{p^{*}}=\frac{(1-\alpha)\left(\beta d-p^{*}\right)}{p^{*}} \leq 0 .
\end{aligned}
$$

Therefore, the borrowers chooses $t_{H}=0$.

If $\alpha=1$, the first order condition becomes

$$
\beta \pi_{H} \frac{\left(\mathbb{E}(\theta)-\theta_{L}\right)}{\left(1-\theta_{L}\right)} v_{2}^{B}\left(\frac{\beta \hat{v}_{2}^{L}}{p^{*}}-1\right)=0,
$$

since $\frac{\beta \hat{v}_{2}^{L}}{p^{*}}-1=0$ and the borrower is indifferent between any value of $t_{H} \in[0, a]$. Note that since $r_{L}=\theta_{L} q$ and $r_{H}>r_{L}$, not reporting the truth in the low state is not feasible and the incentive compatibility constraint in the low state can be ignored.

Proposition 11 Choosing a funding contract at $t=1$ where

$$
\begin{aligned}
q_{1}^{*} & =\frac{a}{1-\theta_{L}}\left(d+\beta\left(\frac{\hat{d}+\pi_{H}\left(v_{2}^{B}-\hat{v}_{2}^{L}\right)+\alpha \pi_{L}\left(\frac{\beta v_{2}^{B}}{p^{*}}-1\right) \hat{v}_{2}^{L}}{\left(1+\alpha\left(\frac{\beta v_{2}^{B}}{p^{*}}-1\right)\right)}\right)\right) \\
r_{1 L}^{*} & =\theta_{L} q_{1}^{*}, r_{1 H}^{*}=\theta_{L} q_{1}^{*}+d a+\frac{\beta v_{2}^{B} a}{\left((1-\alpha)+\beta v_{2}^{B} \alpha\right)} \\
t_{1 L}^{*} & =a_{B}, \text { and } t_{1 H}^{*}=0 .
\end{aligned}
$$

is optimal for the borrower. This is the unique optimal contract if $\alpha \in[0,1)$.

Proof. The proof follows directly from Lemmas 5 and 6 in this subsection.

\subsection{Proof of Proposition 4}

The liquidity and collateral premia the borrower attaches to the asset at $t=1$ are, respectively, 


$$
\left(\frac{\mathbb{E}(\theta)-1}{1-\theta_{L}}(1+\beta) d+\frac{\mathbb{E}(\theta)-\theta_{L}}{1-\theta_{L}} \beta\left(\hat{v}_{2}^{L}-d\right)+\frac{\mathbb{E}(\theta)-\theta_{L}}{1-\theta_{L}} \alpha\left(\frac{\beta v_{2}^{B}}{p^{*}}-1\right)\left(d+\beta \hat{v}_{2}^{L}\right)\right)
$$

and

$$
\frac{\mathbb{E}(\theta)-\theta_{L}}{1-\theta_{L}} \beta \pi_{H}\left(v_{2}^{B}-\left(1+\alpha\left(\frac{\beta v_{2}^{B}}{p^{*}}-1\right)\right) \hat{v}_{2}^{L}\right) .
$$

From the expressions in $\overline{\mathrm{LP}}$ and $\mathrm{CP}$, it is easy to see that:

$\frac{d \text { Liquidity Premium }}{d \alpha}=$

$$
\frac{\mathbb{E}(\theta)-\theta_{L}}{1-\theta_{L}} \beta\left(1+\alpha\left(\frac{\beta v_{2}^{B}}{p^{*}}-1\right)\right)\left(\frac{p^{*}}{\beta}-d\right)+\frac{\mathbb{E}(\theta)-\theta_{L}}{1-\theta_{L}}\left(\frac{\beta v_{2}^{B}}{p^{*}}-1\right)\left(d+\beta \hat{v}_{2}^{L}\right)>0
$$

and $\frac{d \text { Collateral Premium }}{d \alpha}=$

$$
-\frac{\mathbb{E}(\theta)-\theta_{L}}{1-\theta_{L}} \beta \pi_{H}\left(\left(\frac{\beta v_{2}^{B}}{p^{*}}-1\right) \hat{v}_{2}^{L}+\left(1+\alpha\left(\frac{\beta v_{2}^{B}}{p^{*}}-1\right)\right)\left(\frac{p^{*}}{\beta}-d\right)\right)<0
$$

since

$$
\left(\frac{p^{*}}{\beta}-d\right)>0 \text { and }\left(\frac{\beta v_{2}^{B}}{p^{*}}-1\right)>0 \text { for all } \alpha \in[0,1)
$$

\subsection{Proof of Proposition 6}

The asset's debt capacity is given by:

$$
D=d_{1}+\beta \frac{V_{2}^{L}(a, \bar{d})}{a}+\beta \pi_{H}\left(\frac{V_{2}^{B}\left(a, d_{H}\right)}{a}-\frac{V_{2}^{L}\left(a, d_{H}\right)}{a}\right) .
$$

Since $\frac{V_{2}^{L}(a, d)}{a}=d$,

$$
\frac{\partial D}{\left.\partial d_{H}\right|_{\bar{d}}}=\beta \pi_{H}\left(\frac{\mathbb{E}(\theta)-\theta_{L}}{1-\theta_{L}}-1\right)=\beta \pi_{H} \frac{\mathbb{E}(\theta)-1}{1-\theta_{L}}>0
$$

\subsection{Proof of Proposition 7}

As long as the borrower values the asset more than lender at the end of period 1, the borrower will find it costlier to transfer the asset to lender and, thus, strictly prefer to use the asset as collateral. This happens when:

$$
\rho V_{2}^{B}(a)+(1-\rho) V_{2}^{L}(a)>\rho V_{2}^{L}(a)+(1-\rho) V_{2}^{B}(a),
$$

which is the same as $0.5<\rho$, since $V_{2}^{L}(a)<V_{2}^{B}(a)$. 


\subsection{Proof of Proposition 8}

This proof of follows directly from the Proposition 13 at the end of this section which requires the characterization of the equilibrium in the dynamic model. The following Lemmas and Proposition characterize the optimal contract in the dynamic version of the model and yield the proof of Proposition 8 .

By inspecting the constraints in the borrower's problem, it can be considerably simplified. First, in any equilibrium, the participation constraint for the lender's participation constraint will hold with equality. If it did not, the borrower could increase the loan amount and increase his expected utility without violating any of the additional constraints. As is typical in this kind of problems, the incentive compatibility constraint will bind in the high state and $I C_{H}$ will hold with equality. Finally, in order to maximize the size of the loan, the repayment in terms of consumption good in the low state, $r_{L}$, will be the maximum possible, i.e., $r_{L}=\theta_{L} q+d a_{B}$. Lemmas 7, 8 and 9 formalize these arguments.

Lemma 7 Without loss of generality, PC can be replaced by:

$$
\begin{aligned}
q+\beta V_{L}\left(a_{L}\right)= & \pi_{H}\left(r_{H}+d t_{H}\right)+\beta \pi_{H} V^{L}\left(a_{L}+t_{H}\right) \\
& +\pi_{L}\left(r_{L}+d t_{L}\right)+\beta \pi_{L} V^{L}\left(a_{L}+t_{L}\right),
\end{aligned}
$$

in the borrower's problem.

Proof. Let $V^{*}$ be the solution to the borrower's problem. Let $\left\{V_{j}\right\}_{j \geq 0}$ be such that $\lim _{j \rightarrow \infty} V_{j}=$ $V^{*}$, where:

$$
\begin{gathered}
V_{j}=\mathbb{E}(\theta) q_{j}-\pi_{H}\left(r_{H j}+d t_{H j}\right)-\pi_{L}\left(r_{L j}+d t_{L j}\right)+d a_{B} \\
+\beta \pi_{H} V^{B}\left(a_{B}-t_{H j}\right)+\beta \pi_{L} V^{B}\left(a_{B}-t_{L j}\right)
\end{gathered}
$$

for some feasible and incentive compatible $\left\{q_{j}, r_{L j}, r_{H j}, t_{L j}, t_{H j}\right\}$ that satisfies the participation constraint $P C$. Suppose that for some $j \geq 0,\left(q_{j}, r_{L j}, r_{H j}, t_{L j}, t_{H j}\right)$ is such that $P C$ is slack. Then, one could increase $q_{j}$ and increase $V_{j}$ to $V_{j}^{0}$ while still satisfying all the other constraints. Let $\left\{V_{j}^{\prime}\right\}_{j \geq 0}$ be a sequence identical to $\left\{V_{j}\right\}_{j \geq 0}$ if at $\left(q_{j}, r_{L j}, r_{H j}, t_{L j}, t_{H j}\right) P C$ holds with equality and $V_{j}^{0}$ otherwise. Then, by construction, $V_{j}^{\prime} \geq V_{j}$ and therefore,

$$
\lim _{j \rightarrow \infty} V_{j}^{\prime} \geq \lim _{j \rightarrow \infty} V_{j}=V^{*}
$$

Therefore, I can replace $P C$ by Eq.(7) in the borrower's problem.

Lemma 8 Without loss of generality, the incentive compatibility constraints can be replaced by:

$$
-\left(r_{L}+d t_{L}\right)+\beta V^{B}\left(a_{B}-t_{L}\right)=-\left(r_{H}+d t_{H}\right)+\beta V^{B}\left(a_{B}-t_{H}\right)
$$

in the borrower's problem. 
Proof. Let $V^{*}$ be the solution to the borrower's problem. Let $\left\{V_{j}\right\}_{j \geq 0}$ be such that $\lim _{j \rightarrow \infty} V_{j}=$ $V^{*}$, where:

$$
\begin{gathered}
V_{j}=\mathbb{E}(\theta) q_{j}-\pi_{H}\left(r_{H j}+d t_{H j}\right)-\pi_{L}\left(r_{L j}+d t_{L j}\right)+d a_{B} \\
+\beta \pi_{H} V^{B}\left(a_{B}-t_{H j}\right)+\beta \pi_{L} V^{B}\left(a_{B}-t_{L j}\right)
\end{gathered}
$$

for some feasible and incentive compatible contract $\left\{q_{j}, r_{L j}, r_{H j}, t_{L j}, t_{H j}\right\}$ that satisfies the participation constraint in Eq. (7). Suppose that for some $s \geq 0$, no incentive compatibility constraint binds. Then, there exists $\varepsilon_{s}>0$, such that:

$$
\begin{aligned}
\beta V^{B}\left(a_{B}-t_{H s}\right)-V^{B}\left(a_{B}-t_{L s}\right) & \leq r_{H s}-r_{L s}+\left(\theta_{H}-\theta_{L}\right) \varepsilon_{s} \\
r_{H s}-r_{L s}+\left(\theta_{H}-\theta_{L}\right) \varepsilon_{s} & \leq \beta\left(V^{B}\left(a_{B}-t_{H s}\right)-V^{B}\left(a_{B}-t_{L s}\right)\right) .
\end{aligned}
$$

Replace $\left\{q_{s}, r_{L s}, r_{H s}, t_{L s}, t_{H s}\right\}$ by $\left\{q_{s}+\varepsilon_{s}+\varepsilon_{0}, r_{L s}+\theta_{L} \varepsilon_{s}, r_{H s}+\theta_{H} \varepsilon_{s}, t_{L j}, t_{H j}\right\}$, where $\varepsilon_{0}>0$ is such that the participation constraint binds. This contract still satisfies all the constraints, but it attains a value $V_{s}^{0}>V_{s}$.

If $r_{H s}>r_{L s}, I C_{H}$ is the only relevant incentive compatibility constraint. For all $s$ such that $r_{H s}>r_{L s}$ and $I C_{H}$ is not binding, the previous argument applies and a value $V_{s}^{0}>V_{s}$ can be attained.

Now consider those $s \geq 0$ such that $r_{H} s \leq r_{L} s<\theta_{L} q_{s}+d a_{B}$. If $I C_{L}$ binds, I could keep $r_{H s}-r_{L s_{s}}$ constant by increasing both $r_{L s}$ and $r_{H s}$ and by increasing $q_{s}$ to keep the participation constraint binding, which would result in an increase in the objective function. Let this new value be $V_{s}^{0}$. If for $s \geq 0, r_{H s} \leq r_{L s}=\theta_{L} q_{s}+d a_{B}, I C_{L}$ does not bind unless $I C_{H}$ binds. Suppose $I C_{L}$ binds and $I C_{H}$ does not. Then, I could increase $r_{H s}$ while still satisfying incentive compatibility and relaxing the participation constraint. Therefore, I could increase $q_{s}$, which would increase the objective function and give a value $V_{s}^{0} \geq 0$. Therefore, I could construct a new sequence $\left\{V_{j}^{\prime}\right\}_{j \geq 0}$, $V_{j}^{\prime} \geq V_{j}$, such that $V_{j}^{\prime}=V_{j}$ is the incentive compatibility constraint in the high state binds and $V_{j}^{\prime}=V_{j}^{0}$ if it does not. By construction,

$$
\lim _{j \rightarrow \infty} V_{j}^{\prime} \geq \lim _{j \rightarrow \infty} V_{j}=V^{*}
$$

Therefore, without loss of generality I can concentrate on those sequences that are feasible in which $I C_{H}$ holds with equality, i.e.,

$$
r_{H_{j}}-r_{L_{j}}=\beta\left(V^{B}\left(a_{B}-t_{H j}\right)-V^{B}\left(a_{B}-t_{L j}\right)\right) \text { for all } j \text {. }
$$

Lemma 9 Without loss of generality, the feasibility constraints on the contingent transfers in consumption good can be replaced by:

$$
r_{L}=\theta_{L} q+d\left(a-t_{L}\right) \text { and } r_{H} \geq 0
$$

in the borrower's problem. 
Proof. By assumption, $q \leq \bar{e}$ will not bind in a solution to the borrower's problem. Using Lemma 7. the participation constraint can be assumed to hold with equality, and using this in the objective function it is easy to see that the objective function is always increasing in the amount of the loan $q$. Using Lemma 8, the incentive compatibility constraint holds with equality, which implies that the upper bound for $q$ is given by the maximum amount that can be repaid in the low state, i.e., by $r_{L}=\theta_{L} q+d\left(a-t_{L}\right)$.

Let $V^{*}$ be a solution to the borrower's problem. Let $\left\{V_{j}\right\}$ be a sequence such that $\lim _{j \rightarrow \infty} V_{j}=$ $V^{*}$ and where:

$$
\begin{aligned}
& V_{j}=(\mathbb{E}(\theta)-1) q_{j}+\beta \pi_{H} V^{L}\left(a_{L}+t_{H j}\right)+\beta \pi_{L} V^{L}\left(a_{L}+t_{L j}\right)+d a_{B} \\
& +\beta \pi_{H} V^{B}\left(a_{B}-t_{H j}\right)+\beta \pi_{L} V^{B}\left(a_{B}-t_{L j}\right)-\beta V^{L}\left(a_{L}\right)
\end{aligned}
$$

for some feasible and incentive compatible that satisfies Eq.(8), and $P C$ with equality, that is that,

$$
\begin{aligned}
r_{L j}= & q_{j}-\beta\left(\pi_{H} V^{L}\left(a_{L}+t_{H j}\right)+\pi_{L} V^{L}\left(a_{L}+t_{L j}\right)\right)-d t_{L j} \\
& -\beta \pi_{H}\left(\left(V^{B}\left(a_{B}-t_{H j}\right)-V^{B}\left(a_{B}-t_{L j}\right)\right)\right)+\beta\left(V^{L}\left(a_{L}\right)\right) \\
r_{H j}= & q_{j}-\beta\left(\pi_{H}\left(V^{L}\left(a_{L}+t_{H j}\right)\right)+\pi_{L} V^{L}\left(a_{L}+t_{L j}\right)\right)-d t_{H j} \\
& -\beta \pi_{L}\left(V^{B}\left(a_{B}-t_{L j}\right)-V^{B}\left(a_{B}-t_{H j}\right)\right)+\beta V^{L}\left(a_{L}\right) .
\end{aligned}
$$

Then, for all $j$, the contract can be summarized by $\left\{q_{j}, t_{L j}, t_{H j}\right\}$. The feasibility constraints for $r_{L}$ and $r_{H}$ imply the following constraints on $q_{j}$ :

$$
\begin{aligned}
q_{j} \leq & \frac{d a_{B}+\beta\left(\pi_{H} V^{L}\left(a_{L}+t_{H j}\right)+\pi_{L} V^{L}\left(a_{L}+t_{L j}\right) \mid \theta_{L}\right)}{1-\theta_{L}}, \\
& +\frac{\beta \pi_{H}\left(V^{B}\left(a_{B}-t_{H j}\right)-V^{B}\left(a_{B}-t_{L j}\right)\right)-\beta V^{L}\left(a_{L}\right)}{1-\theta_{L}}, \\
q_{j} \geq \quad & \beta \pi_{H} V^{L}\left(a_{L}+t_{H j}\right)+\beta \pi_{L} V^{L}\left(a_{L}+t_{L j}\right) \\
& +\pi_{H} \beta\left(V^{B}\left(a_{B}-t_{H j}\right)-V^{B}\left(a_{B}-t_{L j}\right)\right)-\beta V^{L}\left(a_{L}\right), \\
q_{j} \geq \quad & \frac{d a_{B}+\beta \pi_{H} V^{L}\left(a_{L}+t_{H j}\right)+\beta \pi_{L} V^{L}\left(a_{L}+t_{L j}\right)}{1-\theta_{H}} \\
& +\frac{\pi_{L} \beta\left(V^{B}\left(a_{B}-t_{L j}\right)-V^{B}\left(a_{B}-t_{H j}\right)\right)-\beta V^{L}\left(a_{L}\right)}{1-\theta_{H}}, \\
q_{j} \geq & \beta \pi_{H} V^{L}\left(a_{L}+t_{H j}\right)+\beta \pi_{L} V^{L}\left(a_{L}+t_{L j}\right) \\
& -\pi_{L} \beta\left(V^{B}\left(a_{B}-t_{H j}\right)-V^{B}\left(a_{B}-t_{L j}\right)\right)-\beta V^{L}\left(a_{L}\right) .
\end{aligned}
$$

Construct the following sequence $\left\{V_{j}^{\prime}\right\}$ : if $\left\{q_{j}, t_{L j}, t_{H j}\right\}$ is such that Eq. (12) holds with equality, set $V_{j}^{\prime}=V_{j}$. If $\left\{q_{j}, t_{L j}, t_{H j}\right\}$ is such that Eq. 12 is slack, let $V_{j}^{\prime}$ be the value attained by the contract that satisfies Eq. 12 with equality. Since the transfers in terms of consumption good are defined by Eq.(10) and Eq.(11), this contract is still incentive compatible and feasible. Moreover, $q_{j}^{\prime}>q_{j}$ and $V_{j}^{\prime}>V_{j}$. Therefore,

$$
\lim _{j \rightarrow \infty} V_{j}^{\prime} \geq \lim _{j \rightarrow \infty} V_{j}=V^{*}
$$

and without loss of generality I can concentrate on the sequences $\left\{V_{j}\right\}$ as defined above in Eq.(9), such that the loan quantities $\left\{q_{j}\right\}$ satisfy Eq. 12 with equality. Having this constraint hold with 
equality implies that $r_{L j}=\theta_{L} q_{j}+d a_{B}$. Since $q_{j} \geq 0$ always, all contracts along this sequence satisfy $r_{L}>0$, which is the same as satisfying Eq.(13) with strict inequality.

Suppose that for some $j$ Eq. (14) holds with equality. This implies $r_{H j}=\theta_{H} q_{j}$ and since $r_{L j}=\theta_{L} q_{j}$, this implies that the participation constraint is slack, and that the producer is giving the non-producer all the gains from the project. From Lemma 7, there exists a feasible and incentive compatible contract that attains a higher value that contract $j$ and therefore, without loss of generality I can ignore sequences in which for some elements $j$, Eq.(14) holds with equality.

Using the Lemma 9, the borrower's problem in the funding market reduces to choosing only the two asset transfers.

Corollary 3 In an affine equilibrium, the borrower's problem can be rewritten as:

$$
\begin{aligned}
& V_{B}^{a}\left(a_{B}, a_{L}\right)=\sup _{\left(t_{H}, t_{L}\right) \in\left[0, a_{B}\right]^{2}} \frac{\left(\mathbb{E}(\theta)-\theta_{L}\right)}{1-\theta_{L}} d a_{B} \\
& +\frac{\left(\mathbb{E}(\theta)-\theta_{L}\right)}{1-\theta_{L}} \beta\left(\pi_{H} V^{L}\left(a_{L}+t_{H}\right)+\pi_{L} V^{L}\left(a_{L}+t_{L}\right)-V^{L}\left(a_{L}\right)\right) \\
& +\frac{(\mathbb{E}(\theta)-1)}{1-\theta_{L}} \beta \pi_{H}\left(V^{B}\left(a_{B}-t_{H}\right)-V^{B}\left(a_{B}-t_{L}\right)\right) \\
& +\beta\left(\pi_{L} V^{B}\left(a_{B}-t_{L}\right)+\pi_{H} V^{B}\left(a_{B}-t_{H}\right)\right),
\end{aligned}
$$

subject to:

$$
\begin{aligned}
q^{*}= & \frac{d a_{B}+\beta\left(\pi_{H} V^{L}\left(a_{L}+t_{H}\right)+\pi_{L} V^{L}\left(a_{L}+t_{L}\right)\right)}{1-\theta_{L}} \\
& +\frac{\beta \pi_{H}\left(V^{B}\left(a_{B}-t_{H}\right)-V^{B}\left(a_{B}-t_{L}\right)\right)-\beta V^{L}\left(a_{L}\right)}{1-\theta_{L}} \\
q^{*} \geq & \max \left\{0, \beta \pi_{H} V^{L}\left(a_{L}+t_{H}\right)+\beta \pi_{L} V^{L}\left(a_{L}+t_{L}\right)\right. \\
& \left.-\pi_{L} \beta\left(V^{B}\left(a_{B}-t_{H}\right)-V^{B}\left(a_{B}-t_{L}\right)\right)-\beta V^{L}\left(a_{L}\right)\right\} .
\end{aligned}
$$

Proof. It follows directly from Lemma 9 ,

Lemma 10 In an affine equilibrium,

$$
\begin{aligned}
v_{B}= & \frac{\left(\mathbb{E}(\theta)-\theta_{L}\right)}{1-\theta_{L}}\left(d+\beta\left(\pi_{H} v_{L} \frac{\partial t_{H}}{\partial a_{B}}+\pi_{L} v_{L} \frac{\partial t_{L}}{\partial a_{B}}\right)\right) \\
& -\frac{(\mathbb{E}(\theta)-1)}{1-\theta_{L}} \pi_{H} \beta c_{B}\left(\frac{\partial t_{H}}{\partial a_{B}}-\frac{\partial t_{L}}{\partial a_{B}}\right) \\
& +\beta \pi_{H} v_{B}\left(1-\frac{\partial t_{H}}{\partial a_{B}}\right)+\beta \pi_{L} v_{L}\left(1-\frac{\partial t_{L}}{\partial a_{B}}\right) .
\end{aligned}
$$

Proof. Using Corollary 3, in an affine equilibrium, the value of a borrower who enters the loan market with $a_{B}$ units of the asset and is matched with a lender with $a_{L}$ units of the asset is: 


$$
\begin{aligned}
V^{B}\left(a_{B}\right)= & \max _{t_{H}, t_{L} \in\left[0, a_{B}\right]^{2}}(\mathbb{E}(\theta)-1) q^{*}+d a_{B}+\beta\left(\pi_{H} v_{L} t_{H}+\pi_{H} v_{L} t_{L}\right) \\
& +\beta \pi_{H} v_{B}\left(a_{B}-t_{H}\right)+\beta \pi_{L} v_{B}\left(a_{B}-t_{L}\right) \\
& +\beta\left(v_{B}-\left(d+\beta v_{L}\right)\right)
\end{aligned}
$$

subject to:

$$
\begin{aligned}
q^{*} & =\frac{d a_{B}+\beta v_{L}\left(\pi_{H} t_{H}+\pi_{L} t_{L}\right)-\pi_{H} \beta c v_{B}\left(t_{H}-t_{L}\right)}{1-\theta_{L}} \\
q^{*} & \geq \max \left\{\beta v_{L}\left(\pi_{H} t_{H}+\pi_{L} t_{L}\right)+\pi_{L} \beta v_{B}\left(t_{H}-t_{L}\right), 0\right\} \\
r_{H} & =q^{*}-\beta \pi_{H} v_{L} t_{H}-\beta \pi_{L} v_{L} t_{L}+\pi_{L} \beta v_{B}\left(t_{H}-t_{L}\right)-d t_{H} \\
r_{L} & =q^{*}-\beta \pi_{H} v_{L} t_{H}-\beta \pi_{L} v_{L} t_{L}+\pi_{H} \beta v_{B}\left(t_{H}-t_{L}\right)-d t_{L} .
\end{aligned}
$$

Given the affine specification of the utility functions, the solution to the borrower's problem will be in corner solution. If the constraint in Eq. 18] is ignored, there are four possible solutions: $t_{L}=0=t_{H}, t_{L}=0$ and $t_{H}=a_{B}, t_{L}=a_{B}$ and $t_{H}=0$, and $t_{L}=a_{B}=t_{H}$. If $t_{L} \geq t_{H}$ then the constraints on $q$ are satisfied. If $t_{L}<t_{H}$, Eq. 18 might bind. Suppose Eq. (18) binds, then,

$$
\frac{d a_{B}+\theta_{L} \beta\left(\pi_{H} v_{L} t_{H}+\pi_{L} v_{L} t_{L}\right)}{\beta c_{B}}=t_{H}-t_{L}
$$

If $r_{H}=0$,

$$
q^{*}=\beta c_{L}\left(\pi_{H} t_{H}-\pi_{L} t_{L}\right)\left(1-\theta_{L}\right)+\pi_{L} d a_{B}
$$

and using the definition of $q^{*}$ together with Eq. (11), this implies:

$$
q^{*}=\frac{\pi_{L} d a_{B}+\beta\left(\pi_{H} v_{L} t_{H}+\pi_{L} v_{L} t_{L}\right)\left(1-\pi_{H} \theta_{L}\right)}{1-\theta_{L}} .
$$

Putting these last two equations together gives:

$$
\beta\left(\pi_{H} v_{L} t_{H}+\pi_{L} v_{L} t_{L}\right)\left(2-\pi_{H}-\theta_{L}\right) \theta_{L}=-\theta_{L} \pi_{L} d a_{B}
$$

which implies $\pi_{H} v_{L} t_{H}+\pi_{L} v_{L} t_{L}<0$, a contradiction. Therefore, Eq. (18) cannot bind in equilibrium and using the guessed functional form for $V^{B}\left(a_{B}\right)$ and matching coefficients gives the result.

The following four lemmas characterize the optimal funding contract.

Lemma 11 In equilibrium, $t_{L} \neq 0$.

Proof. Suppose $t_{L}=0$ in equilibrium. If the objective function is decreasing in $t_{L}$, then it is also decreasing in $t_{H}$. Therefore, $t_{L}=0$ implies $t_{H}=0$. The coefficients of the value functions in Eq. 16 in Lemma 10 would become:

$$
v_{B}=\frac{\left(\mathbb{E}(\theta)-\theta_{L}\right)}{1-\theta_{L}} \frac{d}{1-\beta}
$$

where the marginal valuation of the asset depends on the state only through the dividend level $d$ (and are linear in it). 
The derivative of the objective function with respect to $t_{L}$ is:

$$
\frac{\left(\mathbb{E}(\theta)-\theta_{L}\right)}{1-\theta_{L}} \beta \pi_{L} v_{L}+\frac{(\mathbb{E}(\theta)-1)}{1-\theta_{L}} \pi_{H} \beta v_{B}-\beta \pi_{L} v_{B}
$$

If $t_{L}=0$ and $t_{H}=0$ this becomes:

$$
\begin{aligned}
& \frac{\left(\mathbb{E}(\theta)-\theta_{L}\right)}{1-\theta_{L}} \frac{\beta \pi_{L}}{1-\beta}\left(\frac{\left(\mathbb{E}(\theta)-\theta_{L}\right)}{1-\theta_{L}} \frac{d}{1-\beta}\right) \\
& +\frac{\left(\mathbb{E}(\theta)-\theta_{L}\right)}{1-\theta_{L}} \frac{(\mathbb{E}(\theta)-1)}{1-\theta_{L}} \pi_{H} \beta\left(\frac{d}{1-\beta}\right),
\end{aligned}
$$

which is $>0$ and therefore contradicts $t_{L}=0$.

Proof of Lemma 2 The proof of this Lemma follows from the first-order conditions of the borrower's problem in the funding market using Lemma 10 and Lemma 11.

Lemma $12 t_{L}=a_{B}=t_{H}$ is not an equilibrium.

Proof. Suppose $t_{L}=a_{B}=t_{H}$ in equilibrium. Then, we would have $v_{B}=\frac{\left(\mathbb{E}(\theta)-\theta_{L}\right)}{1-\theta_{L}}\left(d+\beta v_{L}\right)$, which yields $v_{B}=\frac{\left(\mathbb{E}(\theta)-\theta_{L}\right)}{1-\theta_{L}} \frac{d}{(1-\beta)}$. Moreover, this implies

$$
v_{L}-v_{B}=\left(-\frac{(\mathbb{E}(\theta)-1)}{1-\theta_{L}} \frac{d}{1-\beta}\right)<0
$$

which implies that the derivative of the objective function is decreasing in $t_{H}$ and, thus, $t_{H}=0$, which is a contradiction.

Proposition 12 In the only affine equilibrium, $t_{L}^{*}=a_{B}$ and $t_{H}^{*}=0$.

Proof. From the previous lemmas in this section, the only candidate left for equilibrium is $t_{L}^{*}=a_{B}$ and $t_{H}^{*}=0$. Assume $t_{L}^{*}=a_{B}$ and $t_{H}^{*}=0$. Then, Eq. 16 becomes:

$$
v_{B}=\frac{\frac{\left(\mathbb{E}(\theta)-\theta_{L}\right)}{1-\theta_{L}}\left(d+\beta \pi_{L} v_{L}\right)}{1-\beta \pi_{H} \frac{\left(\mathbb{E}(\theta)-\theta_{L}\right)}{1-\theta_{L}}} .
$$

To have $t_{L}^{*}=a_{B}$ and $t_{H}^{*}=0$ be chosen by the producer, the objective function must be increasing in $t_{L}$ and decreasing in $t_{H}$, i.e., the $\mathrm{FOC}$ with respect to $t_{L}$ is

$$
\frac{\mathbb{E}(\theta)-\theta_{L}}{1-\theta_{L}} \beta \pi_{L} v_{L}-\beta \pi_{L} v_{B}+\frac{\mathbb{E}(\theta)-1}{1-\theta_{L}} \beta \pi_{H} v_{B}>0
$$

and the FOC with respect to $t_{H}$ is

$$
\frac{\mathbb{E}(\theta)-\theta_{L}}{1-\theta_{L}} \beta\left(v_{L}-v_{B}\right)
$$

The sign of the derivative of the objective function with respect to $t_{H}$ depends on the sign of the difference in marginal valuations between the borrower and the lender. This difference can be rewritten as:

$$
v_{L}-v_{B}=\frac{d}{1-\beta}-v_{B}<\frac{\beta\left(1-\frac{\mathbb{E}(\theta)-\theta_{L}}{1-\theta_{L}}\right)}{1-\beta \pi_{H} \frac{\left(\mathbb{E}(\theta)-\theta_{L}\right)}{1-\theta_{L}}} \frac{d}{1-\beta}<0 .
$$

Therefore, if the contract implied by $t_{L}^{*}=a_{B}$ and $t_{H}^{*}=0$ is a solution to the borrower's problem in the funding market. 
Proposition 13 In an affine equilibrium, the optimal loan contract $\left(q^{*}, r_{L}^{*}, r_{H}^{*}, t_{L}^{*}, t_{H}^{*}\right)$ is given by:

$$
\begin{gathered}
q^{*}=\frac{\left(d+\beta \pi_{L} v_{L}+\beta \pi_{H} v_{B}\right)}{1-\theta_{L}} a_{B} \\
r_{L}^{*}=\theta_{L} q^{*} \\
r_{H}^{*}=r_{L}^{*}+\beta v_{B} a_{B} \\
t_{L}^{*}=a_{B}, t_{H}^{*}=0 .
\end{gathered}
$$

Proof. The proof follows directly from the lemmas and propositions in this section.

\subsection{Proof of Proposition 9}

Suppose there are $T$ periods in the economy. If there is only one period left in the economy, as is the case in the baseline model, the collateral premium is:

$$
\frac{\mathbb{E}(\theta)-\theta_{L}}{1-\theta_{L}} \beta \pi_{H}\left(v_{B, T}-v_{L, T}\right)=\beta \pi_{H} \frac{\mathbb{E}(\theta)-\theta_{L}}{1-\theta_{L}} \frac{\mathbb{E}(\theta)-1}{1-\theta_{L}} d,
$$

where $v_{i, t}$ is the is the marginal value of the asset for agent $i=B, L$ at the beginning of period $t$. Note that:

$$
v_{B, T-1}=\frac{\mathbb{E}(\theta)-\theta_{L}}{1-\theta_{L}}\left(d(1+\beta)+\beta \pi_{H}\left(v_{B, T}-v_{L, T}\right)\right),
$$

since at $T-1$, holding the asset allows the borrower to pledge the asset's dividends, to credibly commit to repay the lender $\left(v_{B, T}-v_{L, T}\right)$ if the high state is realized and to lever up this amount. Then, if there are $s+1$ periods left, the collateral premium is:

$$
\frac{\mathbb{E}(\theta)-\theta_{L}}{1-\theta_{L}} \beta \pi_{H}\left(v_{B, T-s}-v_{L, T-s}\right)=\frac{\mathbb{E}(\theta)-\theta_{L}}{1-\theta_{L}} \beta \pi_{H}\left(\frac{1-\left(\beta \pi_{H}\right)^{s}}{\left(1-\beta \pi_{H} \frac{\mathbb{E}(\theta)-\theta_{L}}{1-\theta_{L}}\right)}\right) \frac{\mathbb{E}(\theta)-1}{1-\theta_{L}} d .
$$

The derivative with respect to $s$ is:

$$
\frac{\mathbb{E}(\theta)-\theta_{L}}{1-\theta_{L}} \beta \pi_{H}\left(\frac{-\left(\beta \pi_{H}\right)^{s} \ln \left(\beta \pi_{H}\right)}{\left(1-\beta \pi_{H} \frac{\mathbb{E}(\theta)-\theta_{L}}{1-\theta_{L}}\right)}\right) \frac{\mathbb{E}(\theta)-1}{1-\theta_{L}} d>0
$$

since $\beta \pi_{H}<1$. 


\section{References}

Araujo, A., J. Orrillo, and M. R. Pascoa (1994). Equilibirum with default and endogenous collateral. Mathematical Finance 10, 1-21.

Barro, R. (1976). The loan market, collateral, and rates of interest. Joural of Money, Credit and Banking 8 (4), $439-456$.

Bernanke, B. and M. Gertler (1989). Agency costs, net worth, and business fluctuations. American Economic Review 79 (1), 14-31.

Bernanke, B., M. Gertler, and S. Gilchrist (1998). The financial accelerator in a quantitative business cycle framework. Handbook of Macroeconomics, Volume 1, Edited by J..B. Taylor and M. Woodford Volume 1, 1341 - 1393.

Bester, H. (1987). The role of collateral in credit markets with imperfect information. European Economic Review 31, 887-899.

Bolton, P. and D. S. Scharfstein (1990). A theory of predation based on agency problems in financial contracting. American Economic Review 80 (1), 93-106.

Brunnermeier, M. K. and L. H. Pedersen (2009). Market liquidity and funding liquidity. Review of Financial Studies 22 (6), 2201-2238.

Chan, Y.-S. and G. Kanatas (1985). Asymmetric valuations and the role of collateral in loan agreements. Journal of Money. Credit and Banking 17 (1), $84-95$.

Copeland, A., A. Martin, and M. Walker (2011 (revised 2012)). Repo runs: Evidence from the tri-party repo market. Federal Reserve Bank of New York Staff Reports no. 506.

Diamond, D. W. (1984). Financial intermediation and delegated monitoring. Review of Eocnomic Studies, 393-414.

Duffie, D. (1996). Special repo rates. Journal of Finance 51, 493-526.

Fostel, A. and J. Geanakoplos (2008). Leverage cycles and the anxious economy. American Economic Review 98, 1211-44.

Gale, D. and M. Hellwig (1985). Incentive-compatible debt contracts: The one-period problem. Review of Economic Studies 52 (4), 647-663.

Geanakoplos, J. (2003a). Liquidity, default and crashes. Cowles Foundation Paper No. 1074.

Geanakoplos, J. (2003b). Promises promises. Cowles Foundation Paper N0. 1057.

Geanakoplos, J. and W. R. Zame (1997). Collateralized secutiry markets. Working paper, Cowles Foundation, Yale University.

Gorton, G. B. and A. Metrick (2012a). Getting up to speed on the financial crisis: A one-weekendreader's guide. NBER Working Paper Series. 
Gorton, G. B. and A. Metrick (2012b). Securitized banking and the run on repo. Journal of Financial Economics 104 (3), 425 - 451.

Gorton, G. B. and G. Ordoñez (2014). Collateral crises. American Economic Review 104(2), $343-78$.

Gottardi, P., V. Maurin, and C. Monnet (2016). A theory of repurchase agreements, collateral re-use, and repo intermediation. EUI working paper.

Hart, O. and J. Moore (1985). Incomplete contracts and renegotiations. Econometrica 56 (4), $775-785$.

Jermann, U. and V. Quadrini (2012). Macroeconomics effects of financial shocks. American Economic Review 102 (1), $238-71$.

Kiyotaki, N. and J. Moore (1997). Credit cycles. Journal of Political Economy 105, 211 - 48.

Kocherlakota, N. R. (2001). Risky collateral and deposit insurance. Advances in Macroeconomics 1 (1), Article 2.

Lacker, J. M. (2001). Collateralized debt as the optimal contract. Review of Economics Dynamics 4, $842-859$.

Monnet, C. and B. N. Narajabad (2012). Why rent when you can buy? a theory of repurchase agereements. mimeo.

Perri, F. and V. Quadrini (2014). International recessions. mimeo.

Rampini, A. (2005). Default and aggregate income. Journal of Economics Theory 122, 225 - 253.

Rampini, A. (2016). Financing durable assets. NBER Working Paper No. 22324.

Rampini, A. A. and S. Viswanathan (2010). Collateral, risk management, and the distribution of debt capacity. Journal of Finance 65, 2293-2322.

Rampini, A. A. and S. Viswanathan (2013). Collateral and capital structure. Journal of Financial Economics 109(2), 466-492.

Rennison, J. (July 2015b). Us treasuries market faces liquidity concerns. Financial Times.

Rennison, J. (November 2015a). Liquidity deteriorates for us treasuries. Financial Times.

Stiglitz, J. E. and A. Weiss (1981). Credit rationing in markets with imperfect information. American Economic Review 71(3), 393-410.

Townsend, R. M. (1979). Optimal contracts and competitive markets with costly state verification. Journal of Economic Theory 21, 265-293. 